\title{
On the Influence of $\mathrm{Nb} / \mathrm{Ti}$ Ratio on Environmentally- Assisted Crack Growth in High-Strength Nickel- Based Superalloys
}

\author{
A.A.N. NÉMETH, D.J. CRUDDEN, D.M. COLLINS, V. KUKSENKO, \\ C.H. LIEBSCHER, D.E.J. ARMSTRONG, A.J. WILKINSON, and R.C. REED
}

\begin{abstract}
The effect of $\mathrm{Nb} / \mathrm{Ti}$ ratio on environmentally-assisted crack growth of three prototype Ni-based superalloys is studied. For these alloys, the yield strength is unaltered with increasing $\mathrm{Nb} / \mathrm{Ti}$ ratio due to an increase in grain size. This situation has allowed the rationalization of the factors influencing damage tolerance at $700{ }^{\circ} \mathrm{C}$. Primary intergranular cracks have been investigated using energy-dispersive X-ray spectroscopy in a scanning transmission electron microscope and the analysis of electron back-scatter diffraction patterns. Any possible detrimental effect of $\mathrm{Nb}$ on the observed crack tip damage due to Nb-rich oxide formation is not observed. Instead, evidence is presented to indicate that the tertiary $\gamma^{\prime}$-precipitates are dissolving ahead of the crack consistent with the formation of oxides such as alumina and rutile. Our results have implications for alloy design efforts; at any given strength level, both more and less damage-tolerant variants of these alloys can be designed.
\end{abstract}

https://doi.org/10.1007/s11661-018-4619-y

(C) The Author(s) 2018

\section{INTRODUCTION}

BRITTLENESS due to surface-initiated intergranular attack by oxygen is the major limitation to the application of polycrystalline Ni-based superalloys, particularly in the mid-temperature regime of $600{ }^{\circ} \mathrm{C}$ to $800{ }^{\circ} \mathrm{C}^{[1]}$ Hence, crack initiation and/or growth can be accelerated under either static or fatigue loading situations, and therefore this phenomenon is of significant importance for high-temperature applications. ${ }^{[2]}$ Alloying has been found to play a role in alleviating this effect, presumably because the chemical reactions which are promoted are then altered in subtle ways. ${ }^{[3]}$ However, these are not fully understood since the mechanism responsible for intergranular crack propagation is yet to be established. Whilst this is the case, it seems unlikely that the chemistry of these alloys has yet been optimized.

A.A.N. NÉMETH, D.J. CRUDDEN, D.M. COLLINS, V. KUKSENKO, D.E.J. ARMSTRONG, A.J. WILKINSON, and R.C. REED are with the Department of Materials, University of Oxford, Parks Road, Oxford, OX1 3PJ, United Kingdom. Contact e-mail: roger.reed@eng.ox.ac.uk C.H. LIEBSCHER is with the MaxPlanck-Institut für Eisenforschung $\mathrm{GmbH}$, Max-Planck-Straße 1, 40237, Düsseldorf, Germany.

Manuscript submitted October 16, 2017.

Article published online May 11, 2018
Recent work has emphasized the formation of a layered oxide structure consisting of different oxide phases growing ahead of an intergranular crack. This suggests that an oxidation reaction is occurring and that it is not oxygen in its elemental form which is embrittling. ${ }^{[4-6]}$ Thermodynamically less stable oxides consisting of $\mathrm{Ni}$ and $\mathrm{Co}$ are found at the beginning and center of the crack while more stable oxides consisting of $\mathrm{Ti}$ and $\mathrm{Al}$ were found closer to the interface of the oxide and metal. ${ }^{[6]}$ In particular, superalloys containing $\mathrm{Nb}$ are considered susceptible to environmentally-assisted cracking due to the formation of $\mathrm{Nb}$-rich oxides such as $\mathrm{NbO}_{2}$ and $\mathrm{Nb}_{2} \mathrm{O}_{5}$ at the grain boundary ahead of the crack tip. ${ }^{[7,8]}$ But any interpretation is made very much more complex by the interaction of chemistry, microstructure, processing, and the details of the grain boundary reactions which can arise. ${ }^{[9]}$ In addition, damage tolerance arising from microstructure-dependent crack tip shielding and relaxation has to be considered. ${ }^{[10]}$ There are two points which are of overarching importance if progress is to be made towards improved understanding of this effect and hence its alleviation. First, there is a need for systematic experimentation involving the control of the important compositional and microstructural variables such that the effects of others can be isolated, identified, and confirmed. Second, there is a need to better understand the chemical processes occurring at the grain boundaries at the most appropriate lengthscale and with techniques which are capable of providing the most revealing 
information. Scanning transmission electron microscopy/energy-dispersive spectroscopy (STEM-EDS) and high-resolution electron back-scatter diffraction (HR-EBSD) are particularly well suited in this regard, and these are used in the present work.

In this study, three model powder metallurgy (PM) Ni-based superalloys with varying $\mathrm{Nb} / \mathrm{Ti}$ ratio are studied. $\mathrm{Nb}$ partitions to the $\gamma^{\prime}$-phase and in particular the Al site; it also increases the anti-phase boundary (APB) energy and thus is known to promote strength. ${ }^{[1]}$ Ti behaves similarly. Both are strong oxide formers, but their thermodynamic potentials for doing so differ and therefore one might reasonably expect the $\mathrm{Nb} / \mathrm{Ti}$ ratio to influence the damage tolerance displayed by these alloys in oxidative environments. Both, slow strain-rate tests and single edge notch tension tests at $700{ }^{\circ} \mathrm{C}$ were performed, to elucidate the role of $\mathrm{Nb}$ and $\mathrm{Ti}$ on the strength, ductility, and toughness displayed in this system. Miniature testpieces of enhanced surface/volume ratio are employed, in order to accelerate the embrittlement effect and thus facilitate its study. ${ }^{[12]}$

\section{EXPERIMENTAL DESIGN, PROCEDURE, AND RATIONALIZATION}

\section{A. Material}

Three polycrystalline prototype Ni-based superalloys with $\mathrm{Nb}$ /Ti-ratios of $0,0.1$, and 0.4 were studied. Their nominal compositions are shown in Table I. All three alloys were designed with a fixed baseline chemistry and increasing $\mathrm{Nb}$ levels with $\mathrm{Nb}$ being substituted for $\mathrm{Ti}$ on a $1: 1$ basis, using the alloys-by-design of approach ${ }^{[13,14]}$ and deliberately resulting in the same $\gamma^{\prime}$-precipitate volume fraction. Each ABD-alloy was manufactured by ATI powder metals using a lab-scale version of a commercial powder metallurgy process. Powders for each alloy composition were compacted using hot isostatic pressing (HIP) which involved the application of $100 \mathrm{MPa}$ at $1107^{\circ} \mathrm{C}$. These HIP compacts were isothermally forged at $1100{ }^{\circ} \mathrm{C}$ at $0.2 \mathrm{~min}^{-1}$ and then given a super-solvus heat treatment conducted at $1170{ }^{\circ} \mathrm{C}$ for 2 hours followed by a controlled quench of $1{ }^{\circ} \mathrm{C} \mathrm{s}^{-1}$ to $1050{ }^{\circ} \mathrm{C}$. Finally, an aging heat treatment at $850{ }^{\circ} \mathrm{C}$ was performed for 4 hours. Thermodynamic calculations using Thermocalc ${ }^{[15]}$ were performed to estimate the volume fraction of the $\gamma$-phase and $\gamma^{\prime}$-phases resulting from the final aging heat treatment at $850{ }^{\circ} \mathrm{C}$ (see Table I). Only major phases of interest were included from the thermodynamic database: $\gamma, \gamma^{\prime}$, and MC phases, all other phases were suspended. The results are summarized in Table I. The $\gamma^{\prime}$-solvus temperatures were calculated to be $1157^{\circ} \mathrm{C}, 1156^{\circ} \mathrm{C}$, and $1154{ }^{\circ} \mathrm{C}$ with Thermo-Calc using the Thermotech TTNi8 thermodynamic database for ABD-2, ABD-4, and ABD-6, respectively.

The microstructure of each alloy was assessed using SEM and EBSD characterization. Differences in the grain size were observed (Figure 1(a)) and quantified though a Gaussian curve fitted to the grain size distribution obtained from EBSD analysis, see
Figure 1(b). An increase in grain size is induced by increasing the $\mathrm{Nb} / \mathrm{Ti}$ ratio. The mean grain size of each alloy was determined to be $d_{\mathrm{ABD}-2}=18.5 \pm 1.5 \mu \mathrm{m}$, $d_{\mathrm{ABD}-4}=24 \pm 2.5 \mu \mathrm{m}$, and $d_{\mathrm{ABD}-6}=45 \pm 9.7 \mu \mathrm{m}$, respectively, using a grain misorientation threshold of $15 \mathrm{deg}$. The grain boundaries of each ABD alloy were found to be serrated and decorated with $\mathrm{M}_{23} \mathrm{C}_{6}$ (see Figure 1(c)) in addition to intragranular MC. Micrographs of each alloy composition after electro-chemical etching in an aqueous solution of 10 pet phosphoric acid show the intergranular secondary and tertiary $\gamma^{\prime}$-precipitates (see Figure 2). These images were post-processed using ImageJ software ${ }^{[16]}$ to obtain the mean diameter. Unlike grain size which was found to be composition dependent, the size of both secondary and tertiary $\gamma^{\prime}$-precipitates was found to be alloy composition independent. The secondary $\gamma^{\prime}$-precipitates were found to be on average $230 \mathrm{~nm}$ while the tertiary $\gamma^{\prime}$-precipitates had an average diameter of $40 \mathrm{~nm}$. Primary $\gamma^{\prime}$-precipitates were not observed as a result of the supersolvus heat treatment. A composition independent $\gamma^{\prime}$-size distribution was also demonstrated by Collins et al. ${ }^{[17]}$ in his work utilizing the same prototype ABD alloys.

\section{B. Theoretical Modeling of the Yield Stress}

The detailed interpretation which emerges in the rest of the paper relies upon an assessment of the relative contributions to the strengthening of the alloys. Increments to the yield stress will arise from three strengthening mechanisms: (1) Hall-Petch strengthening, (2) solid solution strengthening within the $\gamma$-matrix, and (3) precipitation hardening due to resistance to shearing of the secondary and tertiary $\gamma^{\prime}$-precipitates. Orowan by-passing of the $\gamma^{\prime}$-precipitates is neglected in these alloys. The Hall-Petch effect gives

$$
\sigma_{\mathrm{d}}=\frac{k_{\mathrm{y}}}{\sqrt{d_{\gamma}}},
$$

where $k_{\mathrm{y}}$ is the Hall-Petch coefficient and $d_{\gamma}$ is the mean grain size. In this work, $k_{\mathrm{y}}=501 \mathrm{MPa} \mu \mathrm{m}^{-1 / 2}$ was used, based on work performed on Nimonic 105 with a comparable $\gamma^{\prime}$-phase volume fraction of $f_{\gamma^{\prime}}=$ 47 pct. ${ }^{[18]}$ The strengthening effect due to changes in the $\gamma$-matrix chemistry, $\sigma_{s s}$, was determined using the method of Gypen and Deruyttere ${ }^{[19]}$ using the following equation:

$$
\sigma_{s s}=\left(1-f_{\gamma^{\prime}}\right)\left(\sum_{i} k_{i}^{n} c_{i}\right)^{1 / n},
$$

where $c_{i}$ is the concentration of solute $i$, and $k_{i}$ is the strengthening constant for solute $i$. The value of $n$, a constant, is taken to be $2 / 3 .^{[20]}$ A further increase in the yield stress results from solute atoms acting as frictional obstacles for dislocation slip. The strengthening constants in $\mathrm{Ni}, k_{i}$, have been estimated by Mishima et al. ${ }^{[21]}$ The calculated chemical composition of the $\gamma$-matrix is summarized in Table I for each ABD alloy. The final precipitation shearing stress was estimated 


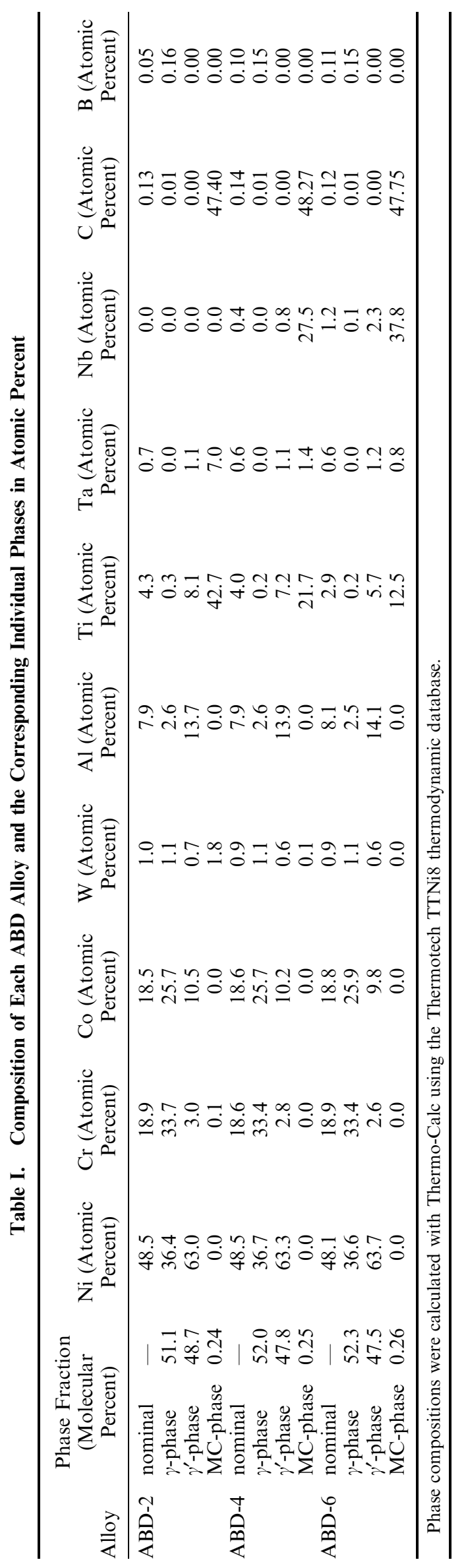



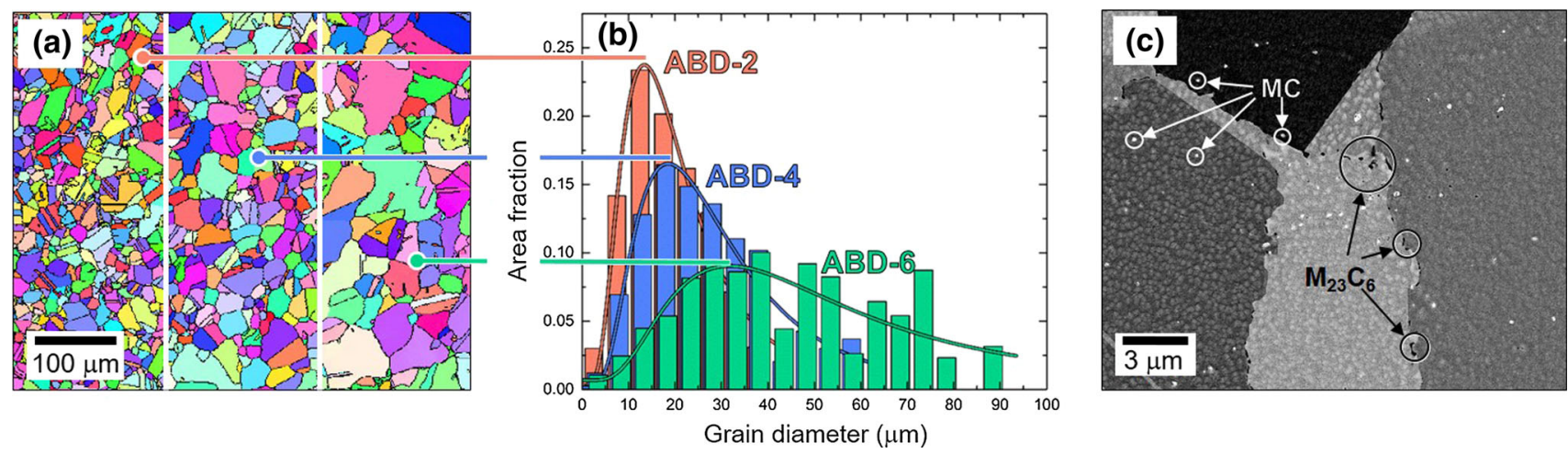

Fig. 1-(a) Inverse pole figure maps of each ABD alloy taken from within a $0.45 \times 0.45 \mathrm{~mm}$ region which was used to study the grain size distribution using EBSD analysis. (b) Measured grain size distribution and Gaussian fit for each ABD alloy using EBSD analysis. (c) Backscattered electron image showing the microstructure of the ABD alloys after the heat treatment cycle. The image was taken on ABD-6. The grain boundaries were found to be serrated and decorated with $\mathrm{M}_{23} \mathrm{C}_{6}$. MC-type carbides were found to be intragranular.
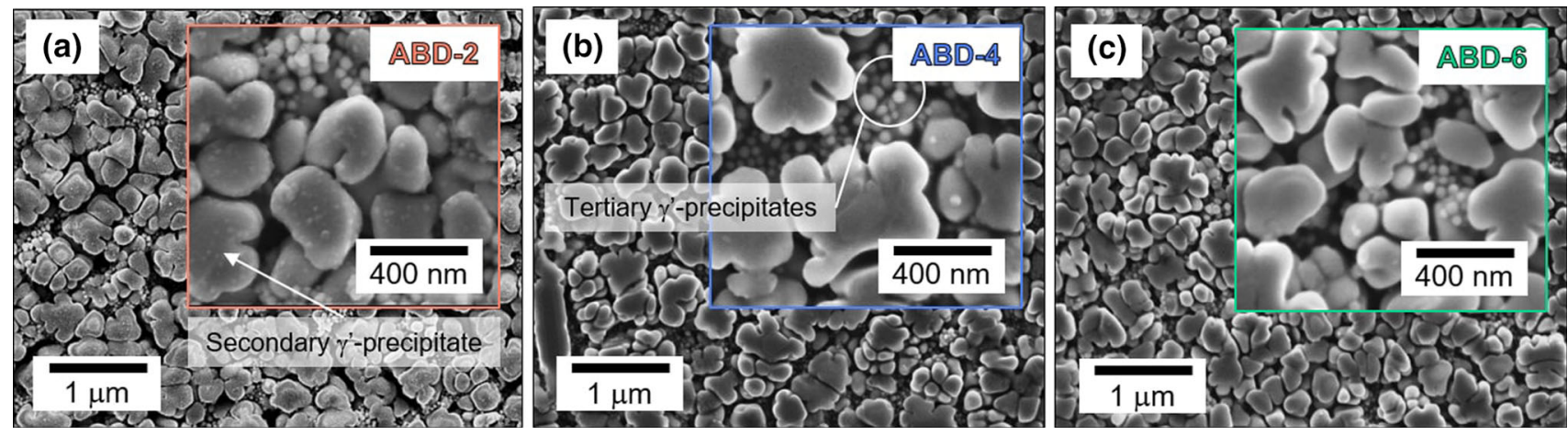

Fig. 2-SEM images of (a) ABD-2, (b) ABD-4, and (c) ABD-6 after electro-chemical etching in an aqueous 10 pct phosphoric acid solution showing coherent intragranular secondary and tertiary $\gamma^{\prime}$-precipitates.

using a model proposed by Galindo-Nava et al. ${ }^{[22]}$ which allows one to calculate the $\gamma^{\prime}$-precipitation hardening contributions using an estimate mean radius for the secondary and tertiary $\gamma^{\prime}$-precipitate size, $r_{\mathrm{s}}$ and $r_{\mathrm{t}}$ :

$$
\sigma_{\mathrm{p}}=M \frac{\gamma_{\mathrm{APB}}}{2 b}\left(w_{\mathrm{s}} \frac{l_{\mathrm{s}}}{\Lambda_{\mathrm{s}}+2 r_{\mathrm{s}}}+w_{\mathrm{t}} \frac{l_{\mathrm{t}}}{\Lambda_{\mathrm{t}}+2 r_{\mathrm{t}}}\right),
$$

where $M$ is the Taylor orientation factor; $\gamma_{\mathrm{APB}}$ is the anti-phase boundary energy of the $\gamma^{\prime}$-phase; $b$ is the magnitude of the Burgers vector; $w_{\mathrm{s}}$ and $w_{\mathrm{t}}$ are the particle number fractions of secondary and tertiary $\gamma^{\prime}$-precipitates; $l_{\mathrm{s}}$ and $l_{\mathrm{t}}$ are the average segment lengths of the leading dislocation acting in the cutting of a secondary and tertiary $\gamma^{\prime}$-precipitate; $\Lambda_{\mathrm{s}}$ and $\Lambda_{\mathrm{t}}$ are the average effective lengths of the leading dislocations driving the secondary and tertiary $\gamma^{\prime}$-precipitate cutting. Values for the Taylor orientation factor and the Burgers vector are taken to be 3 and $0.248 \mathrm{~nm}$, respectively. The anti-phase boundary energy of the $\gamma^{\prime}$-phase at $0 \mathrm{~K}$ was obtained from theoretical predictions employing DFT and is as follows: $\gamma_{\mathrm{APB}}^{\mathrm{ABD}-2}=0.344, \gamma_{\mathrm{APB}}^{\mathrm{ABD}-4}=0.349$, $\gamma_{\mathrm{APB}}^{\mathrm{ABD}-6}=0.36 \mathrm{Jm}^{-2}{ }^{[14]}$ These values were fitted to the following polynomial function to capture the effect of temperature at $700{ }^{\circ} \mathrm{C}$ as proposed by Galindo-Nava et $a .^{[22]}: \quad \gamma_{\mathrm{APB}}=\gamma_{\mathrm{APB}}^{0 \mathrm{~K}}-\left(7 \times 10^{-6} T-3 \times 10^{-8} T^{2}\right)$.
The $\gamma^{\prime}$-precipitate shearing stress is controlled by strong-pair coupling since both $r_{\mathrm{s}}$ and $r_{\mathrm{t}}$ are greater than the particle radius when the maximum strength is defined by $r_{\mathrm{m}}=\mu b^{2} / 2 \gamma_{\mathrm{APB}}$, with $\mu=E /(2(1+v))$ and $v=0.32$. The following analytical expressions were used to capture the effect of temperature $\mu=87.3-9 \times$ $10^{-4} T-1.9 \times 10^{-5} T^{2}{ }^{[22]}$ The length of the leading dislocation cutting the precipitates is expressed as $l=$ $2\left(r^{2}-\left(r-r_{\mathrm{m}}\right)^{2}\right)^{(1 / 2)}$ and the effective length of the leading dislocation driving $\gamma^{\prime}$-precipitate cutting is given by $\Lambda=\max \{\lambda, L-l\}$. $\lambda$ is the Friedel sampling length which is defined by $\lambda=\left(2 T_{\text {ten }} / r \times \gamma_{\mathrm{APB}}\right)$, where $T_{\text {ten }}$ is the dislocation line tension and given by $0.5 \times \mu b^{2}$ and $L$ is the mean particle spacing $L=\left(2 \pi / 3 f_{\gamma^{\prime}}\right)^{1 / 2} \times r$.

\section{Experimental Assessment of the Mechanical Properties}

Tensile testing was conducted at a slow strain-rate of $1 \times 10^{-4} \mathrm{~s}^{-1}$ at room temperature and at $700{ }^{\circ} \mathrm{C}$ using a $5 \mathrm{kN}$ Instron electro-thermal mechanical testing (ETMT) machine. Detailed information relating to the design and operation of the ETMT equipment can be found elsewhere. ${ }^{[23]}$ Miniaturized specimens of cross section $1 \times 1 \mathrm{~mm}^{2}$ and a gauge length of $14 \mathrm{~mm}$ were 
used; the full sample length was $40 \mathrm{~mm}$. Great care was taken with preparation of specimens. These were produced using wire-based electrical discharge machining (EDM), with surfaces subsequently ground to 1200 grit to maintain a consistent surface finish and to remove the recast layer resulting from the EDM process. Consistent with the design of the ETMT machine, specimens were heated using electrical resistance by passing a direct current through the specimen. Temperature measurement during testing was achieved by spot-welding a K-type thermocouple to the central portion of the specimen gauge. A minimum of three tests were performed at each condition, at a constant extension rate consistent with a linear variable displacement transformer (LVDT). The engineering strain was used as a measure of the ductility; engineering strain is defined as follows: $\varepsilon=\left[\left(L_{\mathrm{f}}-L_{0}\right) / L_{0}\right]$, where the gauge length extension $L_{0}-L_{\mathrm{f}}$ was monitored using digital image correlation measurements of a thermal paint pattern applied in the central $5 \mathrm{~mm}$ of the specimen where the temperature and therefore deformation are uniform ${ }^{[12]}$; the engineering stress-strain curves produced were shown to be independent to small changes of $L_{0}$.

To quantify the conditional fracture toughness at $700{ }^{\circ} \mathrm{C}$ in air, additional ETMT testing was carried out using single edge notch tension specimens. The specimens described above were modified by machining a circular notch on one side to a depth of $150 \mu \mathrm{m}$. From this notch, a low cycle fatigue crack was grown at room temperature under load control using an R-ratio of 0.1 and a $2 \mathrm{~Hz}$ sinusoidal cycling waveform. A maximum stress level of 95 pct of $\sigma_{\mathrm{y}}$ was applied. Hereafter the pre-fatigue cracked test pieces were subjected to a constant extension rate of $5 \times 10^{-4} \mathrm{~mm} \mathrm{~s}^{-1}$ at $700{ }^{\circ} \mathrm{C}$ causing the environmentally-assisted growth of the crack. Upon crack growth, tests were interrupted by unloading and simultaneously reducing the temperature to ambient with a cooling rate close to $100{ }^{\circ} \mathrm{C} \mathrm{s}^{-1}$. The conditional fracture toughness, $K_{\mathrm{q}}$, was calculated with conditional load $P_{\mathrm{q}}$ obtained from the load displacement curve and the measured initial crack length, $a$, according to the following equation:

$$
K_{\mathrm{q}}=\frac{P_{\mathrm{q}}}{A} \sqrt{\pi a} \times Y,
$$

where $P_{\mathrm{q}}$ is the maximum load that the specimen could withstand before quasi-brittle crack propagation occurred, and $A$ is the specimen cross section area. The term $Y$ is a geometry factor, taken from Reference 24 and is given by

$$
\begin{aligned}
Y= & 1.12-0.23\left(\frac{a}{w}\right)+10.6\left(\frac{a}{w}\right)^{2} \\
& -21.7\left(\frac{a}{w}\right)^{3}+30.4\left(\frac{a}{w}\right)^{4},
\end{aligned}
$$

where $w$ is the specimen width. The determined conditional fracture toughness, $K_{\mathrm{q}}$, has to be regarded as a geometry-dependent material parameter, due to the amount of crack tip constraint arising due to the miniaturized ETMT tests.

\section{Fractography and Damage Analysis}

The microstructure of each alloy both before and after testing was characterized with a Zeiss Merlin scanning electron microscope (SEM). Secondary backscattered electron imaging and HR-EBSD analysis were used. Diffraction patterns were acquired with a Bruker Quantax EBSD system-at a $800 \times 600$ pixels $^{2}$ resolution to provide suitable angular resolution, and saved for subsequent analysis. Using an in-house method to measure the lattice curvature, the distribution of geometrically necessary dislocations (GNDs) was estimated following Wilkinson et al. ${ }^{[25]}$ Fractography was supported by a Zeiss Merlin FEG SEM equipped with an in-column energy selective backscattered (ESB) detector and an Oxford Instruments XMax $150 \mathrm{~mm}^{2}$ detector for obtaining SEM-EDX elemental maps. Samples for transmission electron microscopy (TEM) were prepared by focused ion beam thinning in a Zeiss Auriga dual beam system. Annular bright-field (ABF) and high angle annular dark field (HAADF) images as well as STEM-EDS elemental maps were acquired in a probe corrected FEI Titan Themis 60-300 microscope equipped with a ChemiSTEM Si-drift EDS-system operated at $300 \mathrm{kV}$. A probe semi-convergence angle of $17 \mathrm{mrad}$ was used to form the electron probe. The semi-collection angles for $\mathrm{ABF}$ and HAADF imaging conditions were chosen to be 8 to 16 and 17 to $73 \mathrm{mrad}$, respectively.

\section{RESULTS}

\section{A. Characterization of the Mechanical Properties}

Engineering stress-strain curves are shown in Figure 3 at both ambient temperature and $700{ }^{\circ} \mathrm{C}$ at a strain-rate of $1 \times 10^{-4} \mathrm{~s}^{-1}$. At room temperature, the alloys showed no significant variation in yield stress, at $935 \pm 10 \mathrm{MPa}$, and ultimate tensile stress (UTS), at $1460 \pm 0 \mathrm{MPa}$; moreover, the tensile ductility showed no dependence on the $\mathrm{Nb} / \mathrm{Ti}$ ratio and was determined to be $26.7 \pm 0.1$ pct. At $700{ }^{\circ} \mathrm{C}$ all three alloys showed the same 0.2 pct proof stress of $792 \pm 3 \mathrm{MPa}$ but the tensile ductility now varied appreciably. The UTS increased with increasing ductility due to the increased amount of work hardening as a function of sample elongation.

For tests at $700{ }^{\circ} \mathrm{C}, \mathrm{ABD}-2$ showed the least ductility at $4.2 \pm 1$ pct whilst ABD-4 showed an increase in ductility to $5.4 \pm 0.6 \mathrm{pct}$. The highest tensile ductility was observed for ABD-6 at $7.8 \pm 1.1$ pct. This is illustrated in Figure 3(b) together with SEM images of cross sections through failed specimens. The tensile properties obtained for each alloy are summarized in Table II. Thus, tensile ductility in the mid-temperature regime increased as a function of the $\mathrm{Nb} / \mathrm{Ti}$ ratio (see Figure 4(a)) despite the alloys all having the same yield stress. The observed loss in ductility in the mid-temperature regime is consistent with recent observations made on other superalloy systems ${ }^{[4,26-28]}$ and can be explained by the occurrence of intergranular quasi-brittle failure. Crack propagation along the grain boundaries at $700{ }^{\circ} \mathrm{C}$ also explains the relatively low conditional fracture 


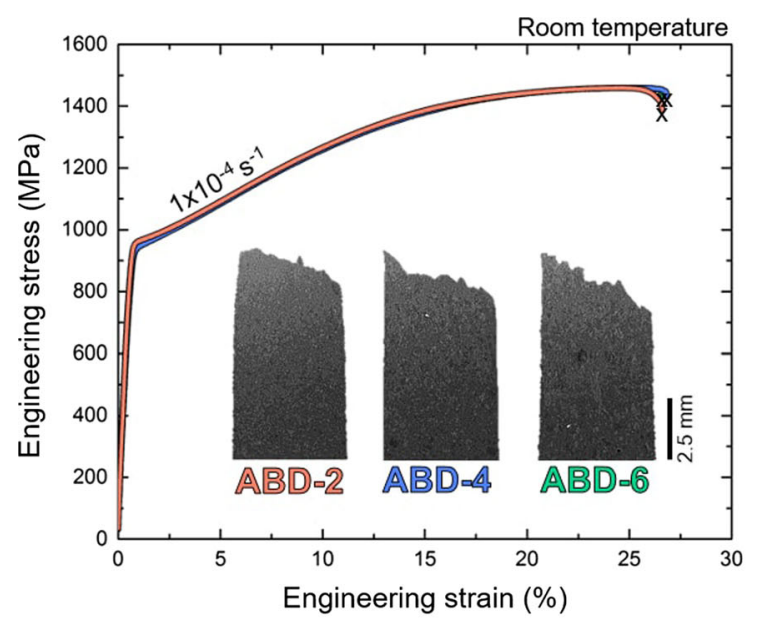

(a)

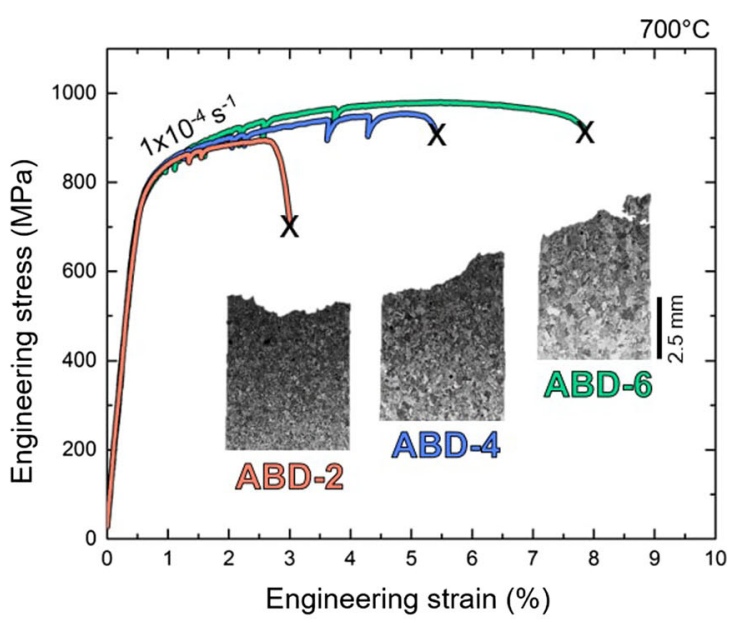

(b)

Fig. 3-(a) Representative stress-strain curves for ABD alloys at room temperature using an initial strain-rate close to $1 \times 10^{-1} \mathrm{~s}^{-1}$. At room temperature, all three ABD alloys experience the same 0.2 pct proof stress and tensile ductility. (b) Representative stress-strain curve for each ABD alloy at $700{ }^{\circ} \mathrm{C}$ and an initial strain-rate close to $1 \times 10^{-4} \mathrm{~s}^{-1}$ showing differences in tensile ductility. Cross sections of the failed specimens are shown.

toughness (see Figure 4(b)). Just like the tensile ductility, toughness increased with increasing $\mathrm{Nb} / \mathrm{Ti}$ ratio. ABD-2 exhibited the lowest conditional fracture toughness with $19.7 \pm 0.5 \mathrm{MPa} \sqrt{\mathrm{m}}$ followed by $21.8 \pm 1.2$ and $24.6 \pm$ $0.4 \mathrm{MPa} \sqrt{\mathrm{m}}$ for ABD-4 and 6, respectively. This is summarized in Table III together with the maximum applied load $P_{\max }$ and the estimate pre-crack length, $a$, from which the conditional fracture toughness $K_{\mathrm{q}}$ was calculated using Eq. [4]. The pre-crack and sample geometry were maintained between the tests so that comparisons between alloys are valid.

The yield stress obtained at $700{ }^{\circ} \mathrm{C}$ is constant regardless of the apparent changes in $\mathrm{Ti} / \mathrm{Nb}$ ratio and grain size. To rationalize this, the yield stress was theoretically assessed for each alloy composition including the three dominant strengthening contributions, as described in Section II-B: (1) Hall-Petch strengthening $\left(\sigma_{\mathrm{d}}\right),(2)$ solid solution strengthening within the $\gamma$-matrix $\left(\sigma_{\mathrm{ss}}\right)$, and (3) resistance to shearing of the secondary and tertiary $\gamma^{\prime}$-precipitates $\left(\sigma_{\mathrm{p}}\right)$. The estimated strengthening contributions for each alloy are summarized in Table IV.

The yield strength modeling predictions are in good agreement with the experimental results. Figure 5 shows the yield stress prediction at $700{ }^{\circ} \mathrm{C}$ and compares it against the experimental results. By comparing individual strength contributions, one can see that $\gamma^{\prime}$-precipitate shearing resistance provides the majority of the strength in the mid-temperature regime whilst Hall-Petch strengthening is the lowest component of the overall yield stress. The predicted strength loss with increasing grain size for ABD-6, a stress decrease of 43 $\mathrm{MPa}$, is counteracted by the increase in the $\gamma^{\prime}$-precipitate shearing stress and $\gamma$-solid solution strengthening resulting in a stress increase of $24 \mathrm{MPa}$. The APB energy of the $\gamma^{\prime}$-phase increases with increasing $\mathrm{Nb}$ additions thereby increasing its resistance to cutting. The results thus far confirm that for alloy of an equivalent strength, there can be substantial difference in ductility and toughness, resulting from changes in phase chemistry and alloy microstructure, in particular grain size.

\section{B. Characterization of Environmentally-Assisted Failure}

The loss in tensile ductility at $700{ }^{\circ} \mathrm{C}$ is associated with an increase in the ease of intergranular crack propagation. Intergranular regions on the fracture surface failed perpendicular to the applied load and showed signs of environmental damage. Regions without environmental damage failed at $45 \mathrm{deg}$ to the tensile axis. Figure 6(a) shows a representative secondary electron SEM image of the intergranular fracture surface at $700{ }^{\circ} \mathrm{C}$ in ABD-2. The fracture surfaces observed for each alloy showed similar characteristics. Secondary cracks branch off the primary crack which led to failure. Secondary cracks were consistently found along high angle grain boundaries which act as preferred paths for crack propagation (Figures 6(b) and (e)). Moreover, SEM-EDS mapping showed that the cracked grain boundaries are decorated with oxidation products, see Figure 6(c). It is suggested that secondary cracks did not propagate at the time of failure. This could have otherwise lead to subsequent oxidation and have altered the damage ahead of the crack tip.

Primary cracks from interrupted miniaturized single-edge notched crack growth tests in alloy ABD-2 and 6 were chosen for further characterization using high-resolution characterization techniques such as EBSD analysis to provide an estimate of the GND density distribution and STEM-EDS mapping for elemental distribution. All characterization was performed along the crack growth direction normal to the crack face in the center of the testpiece (see Figure 7(a)). Figures 7(b) and (c) show two EBSD inverse pole figure maps with respect to the loading direction on 
Table II. Mechanical Properties of Each ABD Alloy When Tested in Laboratory Air with an Initial Strain-Rate of $1 \times 10^{-4} s^{-1}$

\begin{tabular}{lllcr}
\hline Alloy & Temperature $\left({ }^{\circ} \mathrm{C}\right)$ & YS $(\mathrm{MPa})$ & UTS (MPa) & Tensile Ductility (Percent) \\
\hline ABD-2, 4, 6 & 23 & $935 \pm 10$ & $1460 \pm 0$ & $26.7 \pm 0.1$ \\
ABD-2 & 700 & $794 \pm 8$ & $911 \pm 12$ & $4.2 \pm 1$ \\
ABD-4 & 700 & $795 \pm 10$ & $942 \pm 13$ & $5.4 \pm 0.6$ \\
ABD-6 & 700 & $788 \pm 14$ & $979 \pm 5$ & $7.8 \pm 1.1$ \\
\hline
\end{tabular}

Mean results and standard deviation (SD) of a minimum of three test repetitions are given.

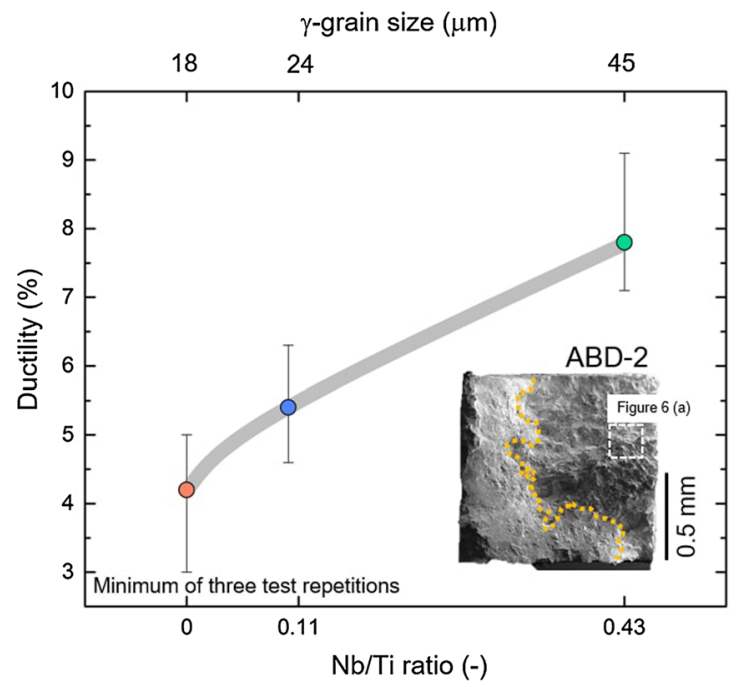

(a)

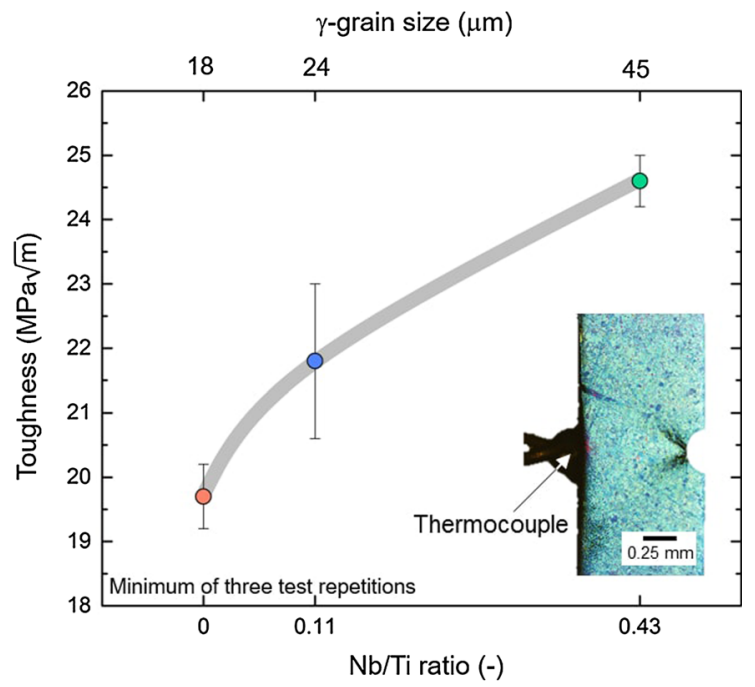

(b)

Fig. 4-(a) Variation in tensile ductility at $700{ }^{\circ} \mathrm{C}$ for slow strain-rate tensile tests performed on ABD alloys. Error bars represent the standard deviation of a minimum of three test repetitions. A SEM image of the fracture surface of ABD-2 shows the surface-initiated intergranular quasi-brittle failure. (b) Variation in conditional fracture toughness, $K_{\mathrm{q}}$, for each ABD alloy at $700{ }^{\circ} \mathrm{C}$. $K_{\mathrm{q}}$ has been calculated from the maximal applied force when pronounced crack growth occurred; error bars represent the standard deviation of a minimum of three test repetitions. A miniaturized single edge notched tension specimen is shown. The thermocouple is attached opposite of the notch location.

Table III. Conditional Fracture Toughness Calculated from the Maximum Obtained Load and the Measured Initial Crack Length for Each ABD Alloy

\begin{tabular}{lccc}
\hline Alloy & $K_{\mathrm{q}}(\mathrm{MPa} \sqrt{\mathrm{m}})$ & $P_{\max }(\mathrm{N})$ & $a_{0}(\mu \mathrm{m})$ \\
\hline ABD-2 & $19.7 \pm 0.5$ & $543 \pm 38$ & $213 \pm 13$ \\
ABD-4 & $21.8 \pm 1.2$ & $621 \pm 35$ & $207 \pm 5$ \\
ABD-6 & $24.6 \pm 0.4$ & $663 \pm 21$ & $220 \pm 0$ \\
\hline
\end{tabular}

Mean results and SD of a minimum of three test repetitions are given.

sections through interrupted primary cracks in ABD-2 and 6 , respectively. A transition from transgranular to intergranular cracking can be observed after the first $\approx 50 \mu \mathrm{m}$. The transgranular crack growing from the notch is a result of the room temperature fatigue pre-cracking. The fine-grained alloy $\mathrm{ABD}-2$ shows a straight fracture path. In contrast, the crack in the coarse-grained ABD- 6 is more tortuous and the opening displacement is reduced. HR-EBSD has been used to calculate an estimate of the GND density distribution with a step size of $450 \mathrm{~nm}$ in a $200 \times 175 \mu \mathrm{m}$ area within
Table IV. Yield Stress Prediction and the Respective Individual Strengthening Contributions for Each ABD Alloy at $700{ }^{\circ} \mathrm{C}$

\begin{tabular}{lcccc}
\hline Alloy & $\begin{array}{c}\text { Yield Stress Prediction } \\
(\mathrm{MPa})\end{array}$ & $\begin{array}{c}\sigma_{\mathrm{d}} \\
(\mathrm{MPa})\end{array}$ & $\begin{array}{c}\sigma_{\mathrm{ss}} \\
(\mathrm{MPa})\end{array}$ & $\begin{array}{c}\sigma_{\mathrm{p}} \\
(\mathrm{MPa})\end{array}$ \\
\hline ABD-2 & 804 & 117 & 156 & 531 \\
ABD-4 & 795 & 99 & 160 & 535 \\
ABD-6 & 786 & 74 & 163 & 548 \\
\hline
\end{tabular}

the wake of each crack. In ABD-2, this area showed a low overall GND density. This is observed in Figure 7(d) and highlights the quasi-brittle nature of the intergranular crack propagation. Regions neighboring the intergranular crack show higher GND densities. In addition, there is evidence of a GND storage at the grain boundaries and at triple junctions indicating some amount of deformation at or near the grain boundaries. Figure 7(e) shows that in ABD-6 the GND storage near grain boundaries is less localized suggesting that intragranular deformation is more pronounced. A high GND 
density is revealed in a bridging grain which is surrounded by the intergranular crack. Figures 7(f) and (g) show a magnified EBSD and GND map of the intergranular crack tip in ABD-6. The GND density distribution here was calculated with a $100 \mathrm{~nm}$ step size showing the accumulation of damage at locations where the grain boundary is serrated and directly ahead of the crack tip. At the tip, the crack is deflected around a smaller grain. In addition, damage accumulation and cracking of a particle, presumably $\mathrm{TiN}$, can be seen within the plastic zone ahead of the crack tip.

To study the nature of the environmental attack leading to the observed intergranular failure, TEM samples were extracted containing a primary crack tip as demonstrated in Figure 8. The Z-contrast HAADFSTEM images shown in Figures 9(a) and (b) illustrate an environmentally-damaged zone ahead of the crack tip.

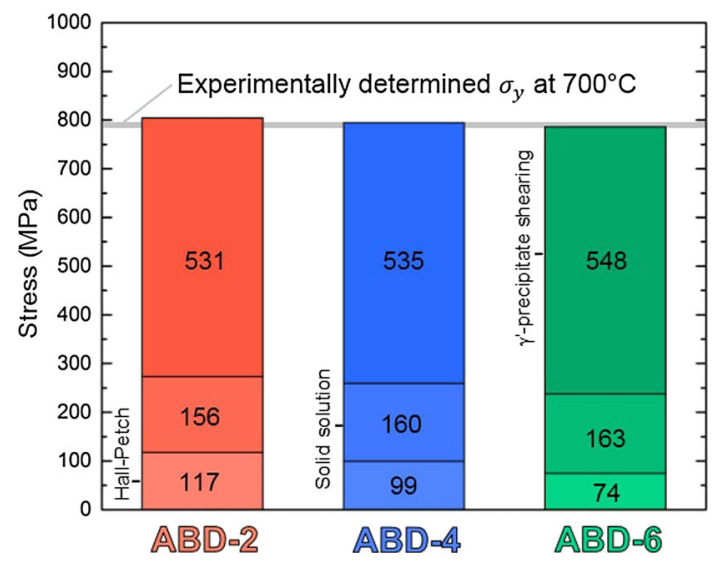

Fig. 5-Model estimation of the individual contributions to the yield strength at $700{ }^{\circ} \mathrm{C}$ and the experimentally determined yield stress for the ABD alloys.
The size of this was found to be independent of alloy composition at a total length of $\approx 770 \mathrm{~nm}$ and a width of $\approx 130 \mathrm{~nm}$ narrowing down into the undamaged grain boundary ahead-while intergranular environmental damage is most pronounced the environmental damage can be observed to penetrate the grains (see Figures 9(c) and (d)). No significant differences in the damage morphology were observed as a function of $\mathrm{Nb} / \mathrm{Ti}$ ratio. Figures 9(e) and (f) show composite STEM-EDS elemental maps. The overlap of $\mathrm{O}-\mathrm{K}_{\alpha}$ and $\mathrm{Cr}-\mathrm{L}_{\alpha} \mathrm{X}$-rays was not found to influence the qualitatively obtained elemental distributions which show the relative elemental distribution integrated over the specimen thickness. More details of the surrounding microstructure such as the tertiary $\gamma^{\prime}$-precipitates are clearly visible in specimen ABD-2 compared to ABD-6. This effect is related to an increased sample thickness of ABD-6. From these images, a $\mathrm{Co}$ and $\mathrm{Cr}$-rich region can be identified mainly in the middle of the damage zone at the $\gamma$-interfaces. Regions which are $\mathrm{Ni}$ - and $\mathrm{Cr}$-rich are present close to the damage zone at the $\gamma^{\prime}$-interfaces. There is evidence suggesting the formation of a distinct $\mathrm{Cr}$-rich oxide layer present in both alloys. In addition, $\mathrm{O}$ is observed to penetrate secondary $\gamma^{\prime}$-precipitates. Internal oxides where found to be Ti and Al-rich. $\mathrm{Nb}$ and $\mathrm{Ta}$ were found to accumulate in the $\gamma^{\prime}$-precipitates but was not observed to concentrate in the O-rich regions. Close to the undamaged grain boundary in ABD-6, a Ti and $\mathrm{Nb}$-rich particle, presumably a laves phase, is shown in Figure 9(f). This particle did not exhibit enhanced oxidation damage.

A Ni-rich single phase tertiary $\gamma^{\prime}$-precipitate free zone is observed in ABD-2 ahead of the environmental damage zone closest to the undamaged grain boundary. This can be observed best in the individual STEM-EDS images in Figures 9(e), 10(b) and (c). Figure 10(b) shows individual STEM-EDS elemental maps and Figure 10(c)
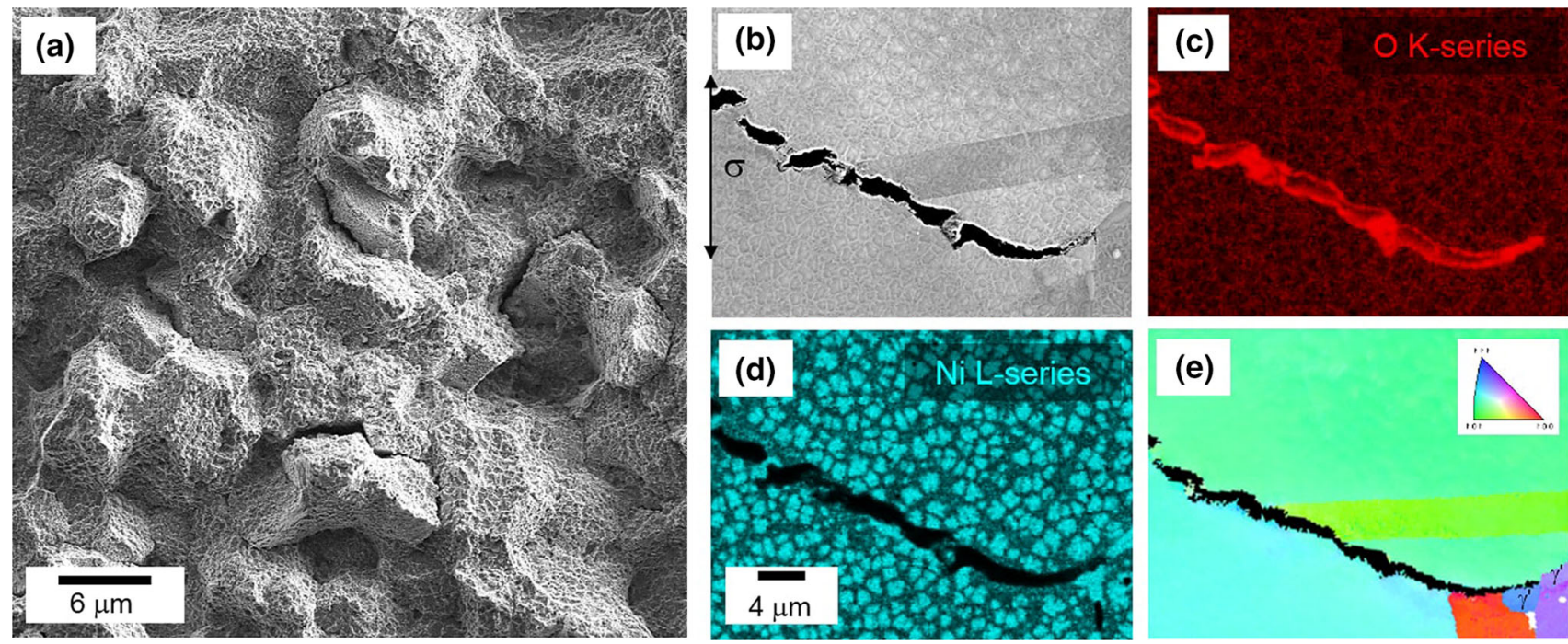

Fig. 6- (a) Example SEM image of an intergranular fracture surface following failure at $700{ }^{\circ} \mathrm{C}$ in ABD-2. Grain contours can be clearly identified. (b) Intergranular secondary cracks close to the fracture surface at $700{ }^{\circ} \mathrm{C}$ in $\mathrm{ABD}-2$. Cracks which propagated primarily along high angle grain boundaries and incoherent primary $\gamma^{\prime}$-interfaces are filled with oxidation products. These observations were confirmed using EDX mapping $(c),(d)$ and EBSD inverse pole figure map with respect to the loading direction $(e)$. 
(a)
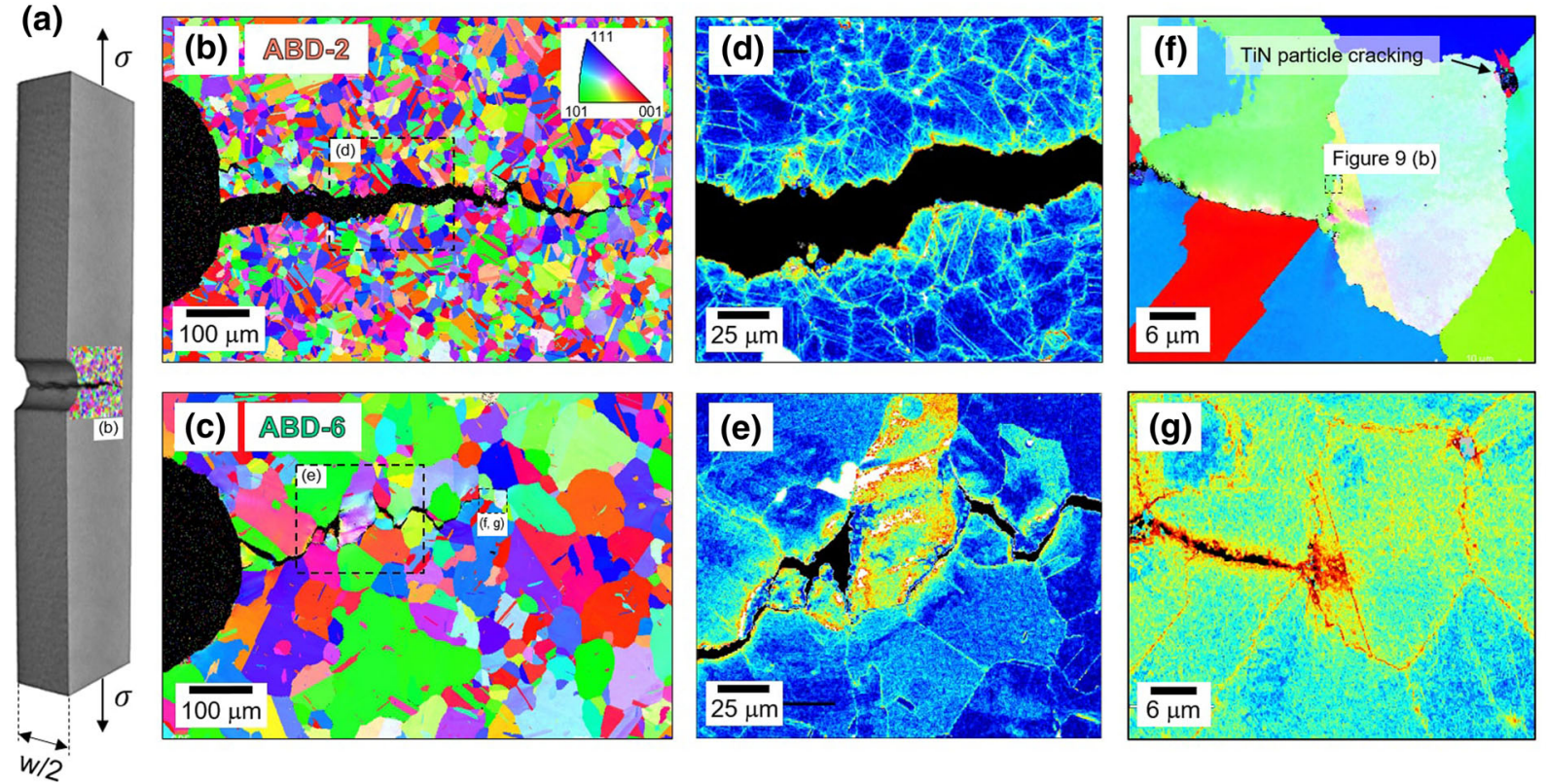

$\approx 13$

Fig. 7-(a) Overview of a interrupted crack growth sample indicating sectioning plane through the center with $w$ being the original sample thickness of $1 \mathrm{~mm} .(b)$ and $(c)$ show inverse pole figure maps with respect to the loading direction on sections normal to the crack face in ABD-2 and 6. Corresponding maps of GND densities calculated from measured lattice curvatures obtained from EBSD maps in the crack wakes are shown in $(d)$ and $(e)$, respectively. $(f)$ Inverse pole figure map with respect to the loading direction of a representative intergranular primary crack tip in ABD-6; $(g)$ shows the corresponding GND density map.

demonstrates the results of a linescan taken across the sub-boundary of the Ni-rich single phase $\gamma^{\prime}$-phase depleted zone. Striking is the observation that oxygen seems to penetrate a sub-boundary along the Ni-rich region and not the grain boundary. At this sub-boundary, an enrichment in $\mathrm{Ti}$ and $\mathrm{Al}$ is observed. $\mathrm{Ni}, \mathrm{Co}$, and $\mathrm{Cr}$ are depleted in this location.

\section{DISCUSSION}

The results presented above demonstrate a relationship between the $\mathrm{Nb} / \mathrm{Ti}$ ratio and the alloys susceptibility to environmentally-assisted cracking at $700{ }^{\circ} \mathrm{C}$. Nonetheless, a number of unresolved issues emerge and these are now considered in this section of the paper.

\section{A. On the Mechanism of Environmentally-Assisted Grain Boundary Embrittlement}

The nature of the mechanism of embrittlement in these alloy systems has been the subject of intense interest; one significant issue is the challenge associated with the choice of most appropriate analytical tool for the characterization of damage. Here, STEM-EDS in the TEM has been employed on carefully prepared crack tips; this combination has been particularly insightful. An environmentally-damaged zone penetrating the grain boundary ahead of primary crack tips has been confirmed; within this the formation of a tertiary $\gamma^{\prime}$-precipitate free-zone is formed which complements the commonly emphasized oxide formation close to the crack tip, which is also observed here. It is this combination of damage which is responsible for intergranular crack propagation which in turn leads to the observed low tensile ductility and low conditional fracture toughness at $700{ }^{\circ} \mathrm{C}$ (Figure 4). But which of these is the more important in controlling the loss of ductility?

Particularly pertinent is the observation that the size and order of the reaction products in the environmentally-damaged zone ahead of the crack tip is independent of the $\mathrm{Nb} / \mathrm{Ti}$ ratio, see Figure 9. The appearance is broadly consistent with the sequence expected from the relative thermodynamic stability of the individual oxidation products, as seen in Figures 9(e) and (f), as reported elsewhere. ${ }^{[4-6,12,29]}$ Thus, an Al-rich oxide $\left(\mathrm{Al}_{2} \mathrm{O}_{3}\right)$ alongside a Ti-rich oxide $\left(\mathrm{TiO}_{2}\right)$ are found closest to the undamaged grain boundary, resulting from the oxidation of these reactive elements which are found in the $\gamma^{\prime}$-precipitates, $\mathrm{Ni}_{3}(\mathrm{Al}, \mathrm{Ti})$. Therefore, these oxides are associated with extension of the environmentally-damaged zone. This is supported by the observation of a tertiary $\gamma^{\prime}$-phase depleted zone which is present ahead of the advancing internal oxide as shown in Figures 10(a) and (b). Unlike during the formation of a surface oxide layer, oxygen is readily available at the furthest extent of the oxide intrusion. Because the metal/ oxide interfaces are aligned parallel to the direction of oxide growth, they act as short-circuits for oxygen diffusion, see Figure 11. Thus, the damage zone extension during steady-state crack propagation is limited by the dissolution of tertiary $\gamma^{\prime}$-precipitates and the migration of $\mathrm{Al}$ and $\mathrm{Ti}$ cations to the oxide/metal interface ahead of the oxide intrusion. For the simple case of $\mathrm{Ni}_{3} \mathrm{Al}$ precipitates, the rate controlling reaction is $\gamma^{\prime} \rightarrow \gamma+\mathrm{Al}_{2} \mathrm{O}_{3}$. The compositional gradient produced 

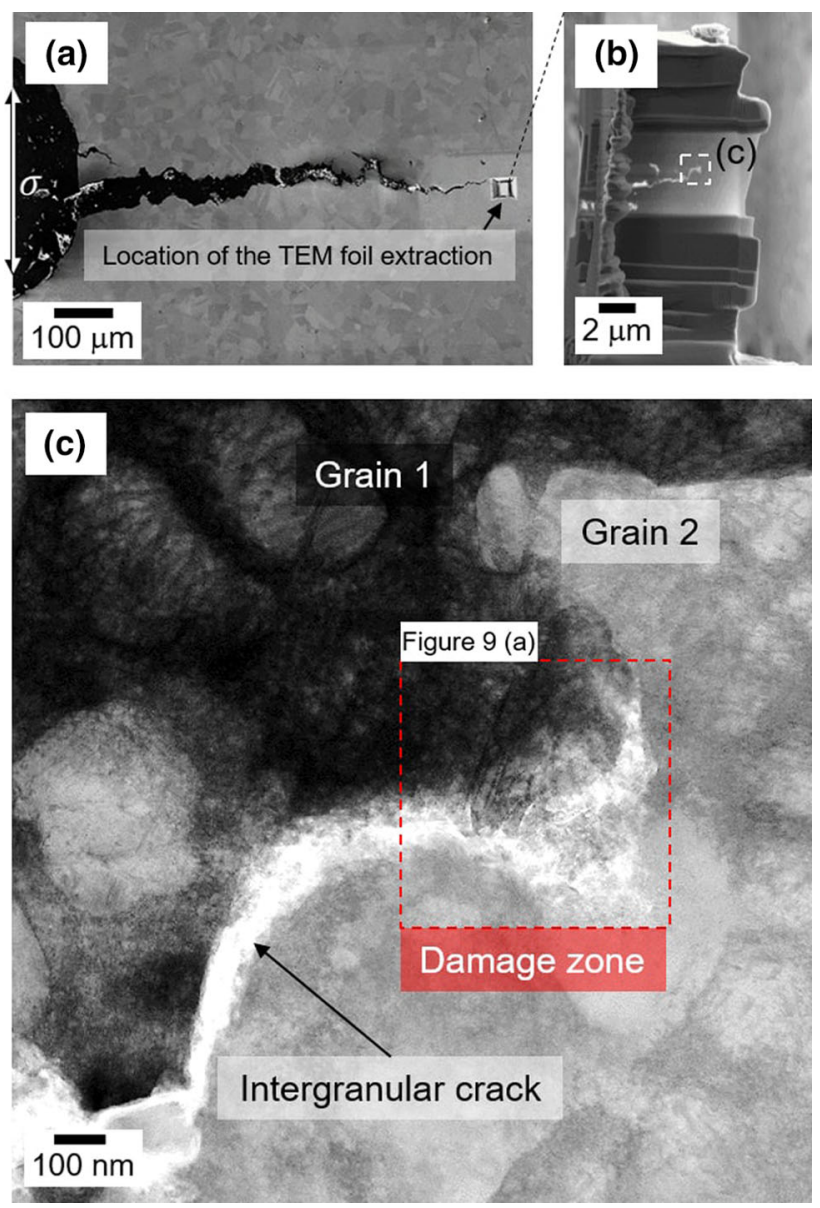

Fig. 8 - (a) SEM image of a cross section though the middle plane of a interrupted miniaturized single-edge notched tensile test in ABD-2. The location of the TEM sample containing the primary crack tip is highlighted. (b) SEM image of the TEM sample imaged at $7 \mathrm{kV}$. (c) Overview ABF-SEM image showing the intergranular nature of the primary crack in ABD-2.

by the depleted zone is assumed to act as an additional driving force for the metal ion diffusion.

It is important to note that the formation of discrete $\mathrm{Nb}$-rich oxides ahead of interrupted primary cracks has not been observed here. Thus, it would appear that any influence of $\mathrm{Nb}$ cannot be attributed to its oxidation. This finding is in contrast to the work of Miller \& Wei et al. ${ }^{[7,8,30,31]}$ who have studied a number of Nb-containing alloys including IN718. They have suggested that even small additions of $\mathrm{Nb}$ increase the susceptibility to environmental-assisted creep crack growth due to the formation of $\mathrm{Nb}$-rich oxides ahead of the crack tip, including $\mathrm{NbO}_{2}$ and $\mathrm{Nb}_{2} \mathrm{O}_{5}$. The results presented here indicate that small additions of $\mathrm{Nb}-$ up to $2.1 \mathrm{wt}$ pct-are however not detrimental and indeed are advantageous. While the formation of $\mathrm{Nb}$-rich oxides is more favored by thermodynamic equilibrium than $\mathrm{TiO}_{2}, \mathrm{Nb}$ is not as abundant $\mathrm{Ti}$ in for example alloy ABD-6 (see Table I) and is believed to stay in solution. Thus, it seems likely that the threshold for $\mathrm{Nb}$ to have any negative effect is associated with the formation of $\gamma^{\prime \prime}$-precipitates, $\mathrm{Ni}_{3} \mathrm{Nb}$, at the grain boundary. Our findings are in agreement with Telesman et al. ${ }^{[32]}$ who showed that hold time crack growth resistance was insensitive to small changes in the $\mathrm{Nb}$ and $\mathrm{Ta}$ contents in Alloy 10.

The above suggests that it is the loss of tertiary $\gamma^{\prime}$-precipitates which is detrimental to the localized mechanical properties. This would explain why the tip of the oxide intrusion in ABD-2 does not follow the prior grain boundary (see Figure 10(b)). It nucleates along what is believed to be a newly formed sub-boundary of the single phase tertiary $\gamma^{\prime}$-precipitate depleted zone. It is likely that this interface is formed due to local deformation-induced recrystallization as suggested by Wlodek et al. ${ }^{[33]}$ The formation of the $\gamma^{\prime}$-phase free zone will be dictated by the tertiary $\gamma^{\prime}$-size and its dissolution kinetics; this is discussed further in Section IV-C.

\section{B. On the Role of Grain Size-Dependent Toughening}

Of significance here is the observed increase in grain size with increasing $\mathrm{Nb} / \mathrm{Ti}$ ratio and its influence on improving the tensile ductility and the conditional fracture toughness. Putting aside for now the issue of why the grain size is influenced by $\mathrm{Nb} / \mathrm{Ti}$ ratio - this is discussed in the following section-what are the implications of this effect?

While a coarser-grained microstructure resulting from a supersolvus heat treatment has been demonstrated to be beneficial - for example by comparing the behavior of any given alloy to sub-solvus and super-solvus processing ${ }^{[9,32,34-36]}$ so far, grain size has not been varied independently of the $\gamma^{\prime}$-precipitate size distribution. This gives rise to the question whether grain size independently improves environmentally-assisted crack growth resistance. The yield stress as well as the mean diameter of the secondary and tertiary $\gamma^{\prime}$-precipitates is approximately constant in the present study, so this makes this analysis possible. The HR-EBSD technique has been used for this purpose in order to characterize the deformation in the crack wakes and also the intergranular crack tips. Both the finer-grained ABD-2 and coarser-grained ABD-6 have been studied, in order to deduce any influence of (i) crack bridging as well as (ii) the grain boundary sliding resistance. While the first mechanism will aid resistance to crack propagation along the environmentally-induced damage zone along an embrittled $\gamma$-boundary, an increase in sliding resistance will retard the build-up of a critical strain ahead of the crack tip.

An influence of crack bridging has indeed been observed in the present work, for example in coarsergrained ABD-6, see Figure 7(e), which exhibits significant evidence of this effect in the crack wake. Plastic deformation is also confirmed in GND density maps of this alloy. By way of comparison, grain bridging is not readily apparent in the finer-grained $\mathrm{ABD}-2$, see Figure 7(d). Bridging grains in the wake of the crack is well known to increase the toughness substantially, by reducing the stress intensity at the crack tip. This finding also explains the post-mortem observation present in the literature of unbroken ligaments on the fracture surfaces of testpieces subjected to mid-temperature dwell fatigue. ${ }^{[37-40]}$ The resulting decrease in crack propagation 


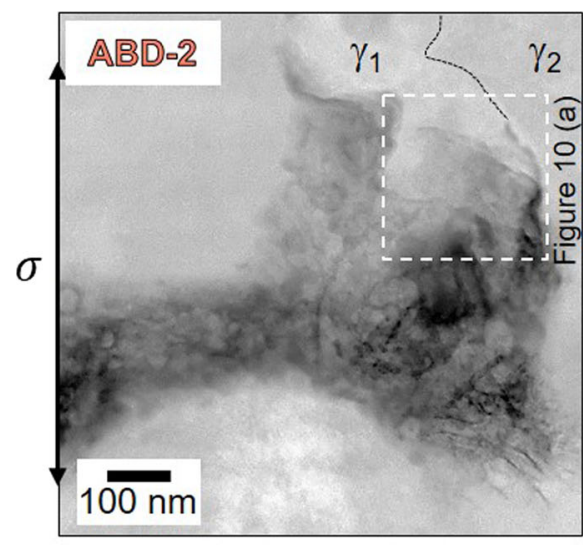

(a)

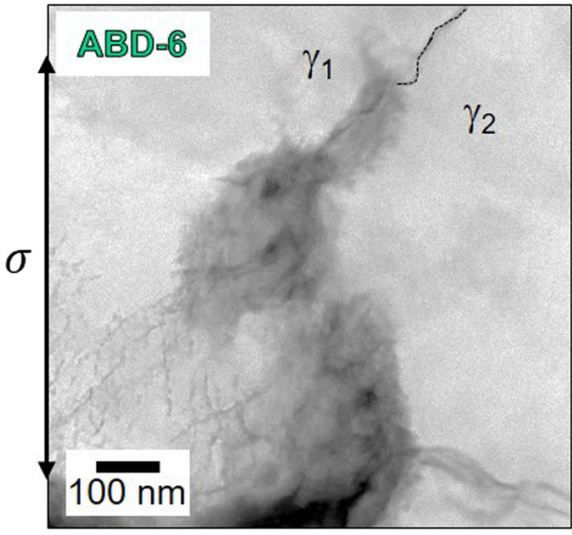

(b)

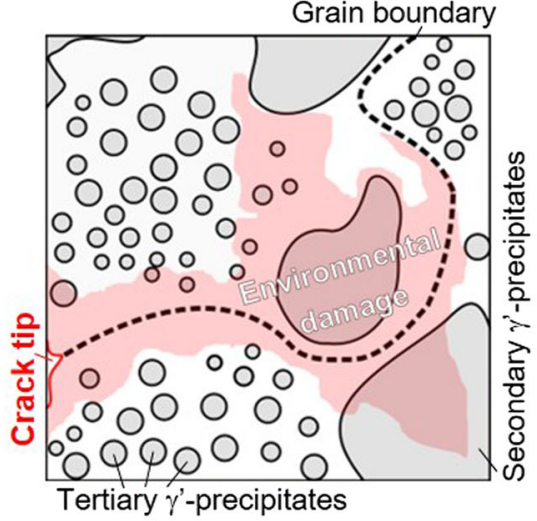

(c)

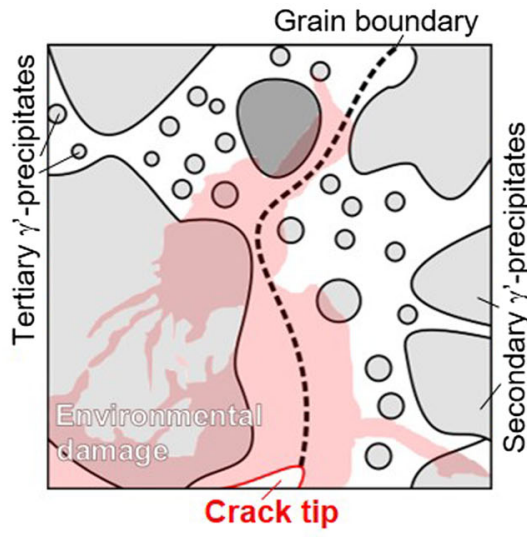

(d)

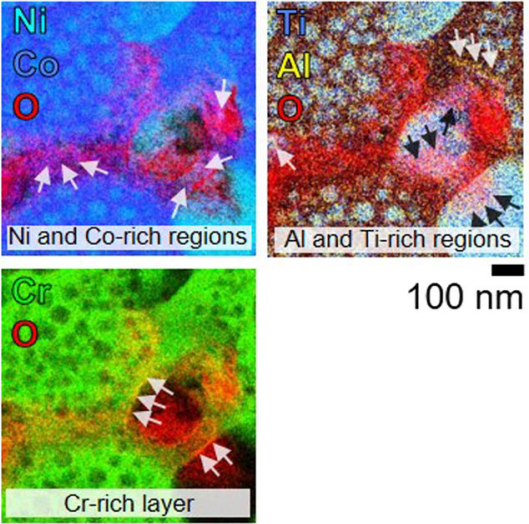

(e)

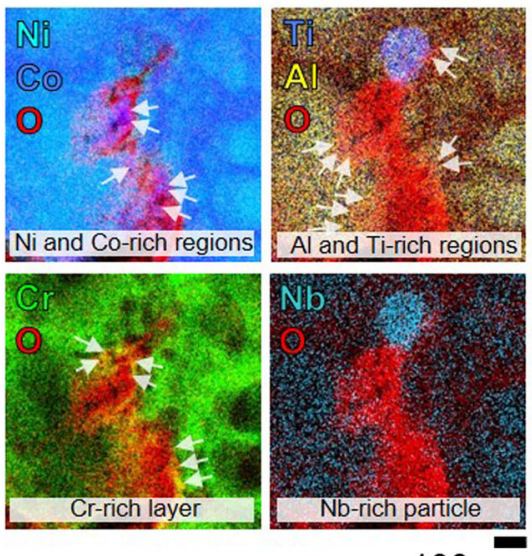

(f)

$100 \mathrm{~nm}$

Fig. 9-HAADF-STEM image of an environmental damage zone ahead of a crack tip in (a) ABD-2 and (b) ABD-6. (c) and (d) show corresponding schematic illustrations highlighting the environmental damage zone ahead of the crack tip. Composite STEM-EDS elemental maps of $\mathrm{O}$ with $\mathrm{Ni}$ and $\mathrm{Co}, \mathrm{Al}$, and $\mathrm{Ti}$ as well as $\mathrm{Cr}$ are illustrated in $(e)$ and $(f)$. The brightest pixels indicate the highest count areas and dark or black areas indicate little or no X-ray counts. The arrows indicate high X-ray count areas.

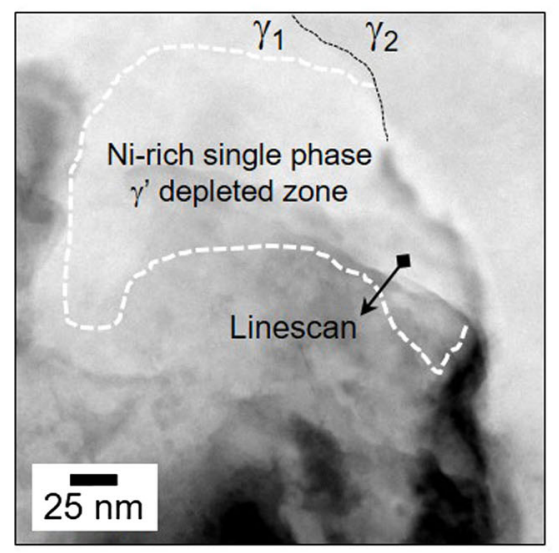

(a)

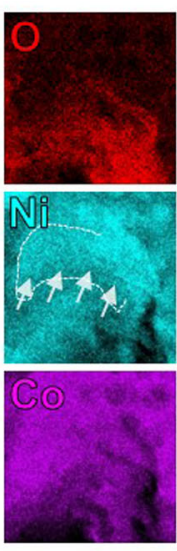

(b)

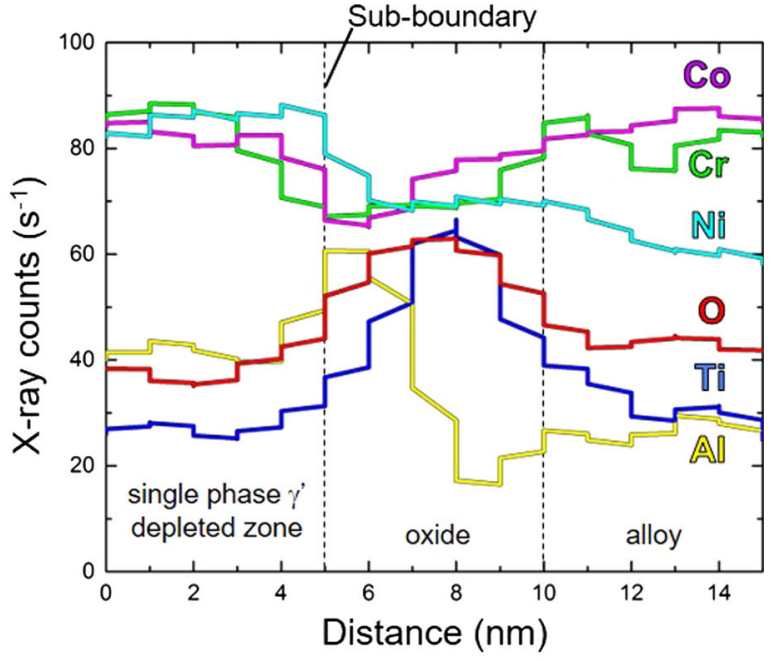

(c)

Fig. 10 - (a) High angle annular dark field STEM image obtained in ABD-2 at the region closest to the undamaged grain boundary shown in Fig. 9(a). Corresponding individual STEM-EDS elemental maps are shown in $(b)$. (c) Linescan obtained across the sub-boundary of the single phase $\gamma^{\prime}$-precipitate depleted zone. A fast Fourier transform filter method was applied to the line profiles. 


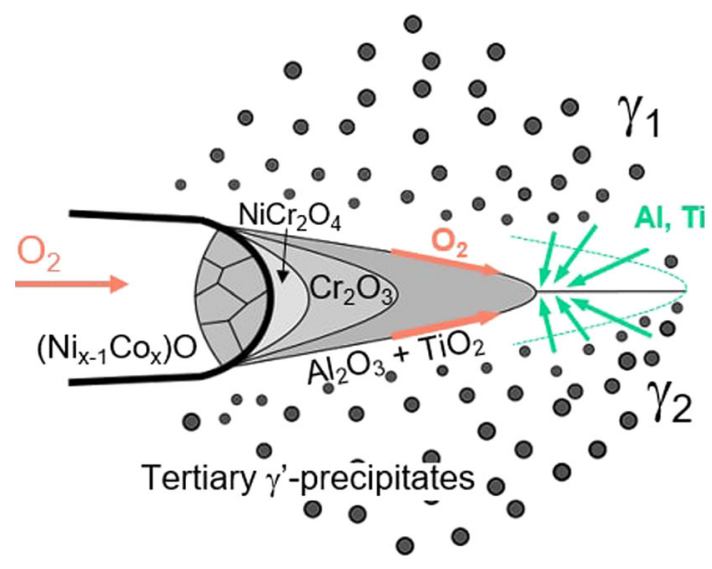

Fig. 11-Schematic diagram of the grain boundary embrittling crack tip oxide in the thermodynamic sequence of $\left(\mathrm{Ni}_{x-1} \mathrm{Co}_{x}\right) \mathrm{O}, \mathrm{NiCr}_{2} \mathrm{O}_{4}$, $\mathrm{Cr}_{2} \mathrm{O}_{3}$, and $\mathrm{Al}_{2} \mathrm{O}_{3}+\mathrm{TiO}_{2}$ adapted by Ref. [4]. Oxygen diffusion along the metal/oxide interfaces and the dissolution of tertiary $\gamma^{\prime}$-precipitates results in the formation of $\mathrm{Al}_{2} \mathrm{O}_{3}$ and $\mathrm{TiO}_{2}$ at the undamaged grain boundary.

driving force will contribute towards the observed increase in toughness and ductility as a function of grain size.

It is emphasized that the observed failure mechanism is likely to be closely related to the underlying deformation process. At $700{ }^{\circ} \mathrm{C}$, plasticity is believed to occur through several independent processes including slip-assisted grain boundary sliding mechanism-due to the absence of stress-relieving mechanisms this leads to intergranular fracture and the observed ductility minimum. ${ }^{[4]}$ The temperature corresponding to the ductility minimum increases with an increased grain size ${ }^{[41]}$ which explains the observed grain size dependency of the tensile ductility in these alloys, see Figure 3(b). In the finer-grained alloy ABD-2, an increase of GND density at the grain boundaries and grain boundary triple junctions suggests more grain boundary deformation compared to the coarser-grained ABD-6, see Figure 7(d). The increase in grain size as well as the grain boundary serrations inhibit intergranular failure by retarding the formation of local microstresses arising from grain boundary deformation. The observed effects of grain size on ductility and toughness agree with predictions based on a critical crack tip strain fracture model proposed by Floreen and Kane ${ }^{[42]}$ where stress intensity at the crack tip, $K$, is proportional to $\left(\sigma_{\mathrm{y}} \times d\right)^{1 / 2}$. A material with a higher resistance to intergranular failure is characterized by a lower strain at the crack tip due to a higher constraint to grain boundary sliding. $\left.{ }^{43}\right]$

\section{On the Relevance to Alloy Design}

This work demonstrates that at $700{ }^{\circ} \mathrm{C}$ - despite a high yield strength - it is possible to design both more (high $\mathrm{Nb} / \mathrm{Ti}$ ) or less (low $\mathrm{Nb} / \mathrm{Ti}$ ) damage-tolerant alloy variants. For optimum resistance to environmentally-assisted cracking, one should aim for a high yield stress and coarse grain size, in as much as the two can be varied independently of one another. As shown here, resistance to $\gamma^{\prime}$-precipitation shearing accounts for the majority of the strength at $700{ }^{\circ} \mathrm{C}$, see Table IV. So what relevance do $\mathrm{Ti}$ and $\mathrm{Nb}$ play in the present case?

Both $\mathrm{Ti}$ and $\mathrm{Nb}$ partition strongly to the $\gamma^{\prime}$-phase, $\mathrm{Ni}_{3}(\mathrm{Al}, \mathrm{Ti}, \mathrm{Nb})$, thus influencing the fraction of $\gamma^{\prime}$-precipitates and the ease of their shearing via changes in the APB energy. ${ }^{[14]}$ This is in agreement with the reported experimental results. To achieve a high tensile strength, the $\gamma^{\prime}$-phase volume fraction the APB energy has to maximized as suggested by Crudden et al. ${ }^{[14]}$ This was done for the alloys designed and studied in this work and can be described by the expression $M_{\text {strength }}=$ $\bar{M} \times 1 / 2 \gamma_{\mathrm{APB}} f^{1 / 2} / b$, where $\bar{M}$ is the Taylor factor; $f$ is the volume fraction of the $\gamma^{\prime}$-phase; $\gamma_{\mathrm{APB}}$ is the anti-phase boundary energy and $b$ is the Burgers vector. For damage tolerance, it is important to account for the reduction of the Hall-Petch contribution due to a coarse supersolvus microstructure which can be described by $\sigma_{\mathrm{HP}}=k_{\mathrm{y}}\left(D_{\text {sub }}^{-1 / 2}-D_{\text {super }}^{-1 / 2}\right)$, where $k_{\mathrm{y}}$ is the Hall-Petch coefficient; $D_{\text {sub }}$ and $D_{\text {super }}$ denote the grain size resulting from a sub-solvus or super-solvus heat treatment. This impact of this is illustrated in Figure 12(a) where strength and ductility for a variety of polycrystalline Ni-based superalloys are plotted. The trade-off between strength and tensile ductility can therefore be described by $M_{\text {strength }}^{*}=\bar{M} \times 1 / 2 \gamma_{\mathrm{APB}} f^{1 / 2} / b-\sigma_{\mathrm{HP}}$, where a grain size-dependent strength reduction is counteracted by a degree of composition-dependent strengthening.

In addition to grain size, the observed dissolution of the tertiary $\gamma^{\prime}$-precipitates during the extension of the environmental damage zone during continuous crack propagation suggests that both size and composition of the tertiary $\gamma^{\prime}$-precipitates influence the susceptibility to embrittlement. Thus, an increase in the mean diameter would result in slower dissolution. This is in agreement with Telesman et al. ${ }^{[45]}$ and Li et al. ${ }^{[9]}$ who have shown that an increase in tertiary $\gamma^{\prime}$-precipitate size is beneficial during dwell fatigue loading. The composition of the tertiary $\gamma^{\prime}$-precipitates is important since the rate of dissolution and the availability of oxidizing elements at the furthest end of the damage zone will be composition dependent. A more stable tertiary $\gamma^{\prime}$-precipitate population ahead of the environmental damage zone will exhibit slower $\gamma^{\prime}$-phase dissolution kinetics and therefore a slower rate of oxide formation. Collins et al. ${ }^{[17]}$ demonstrated that the $\mathrm{Nb}$ present in ABD-6 slows down the formation and dissolution kinetics of the $\gamma^{\prime}$-phase compared to ABD-2. This is in agreement which the results presented here.

A last point relates to the reason why the $\mathrm{Nb} / \mathrm{Ti}$ ratio alters the grain size in this system. It seems likely that this is due to the MC carbide composition, the temperature-dependence of the stability of this phase during forging/subsequent heat treatment and its influence on recrystallization and grain growth. A number of studies have observed the effect of MC carbide composition on the grain size during the processing of polycrystalline Ni-based superalloys and specifically the pinning of grain boundaries by them. ${ }^{[46,47]} \mathrm{A}$ change in the $\mathrm{MC}$ carbide composition from $\mathrm{Ti}$ to $\mathrm{Nb}$-rich $\mathrm{MC}$ carbides is apparent in the thermodynamic predictions of Table I. 


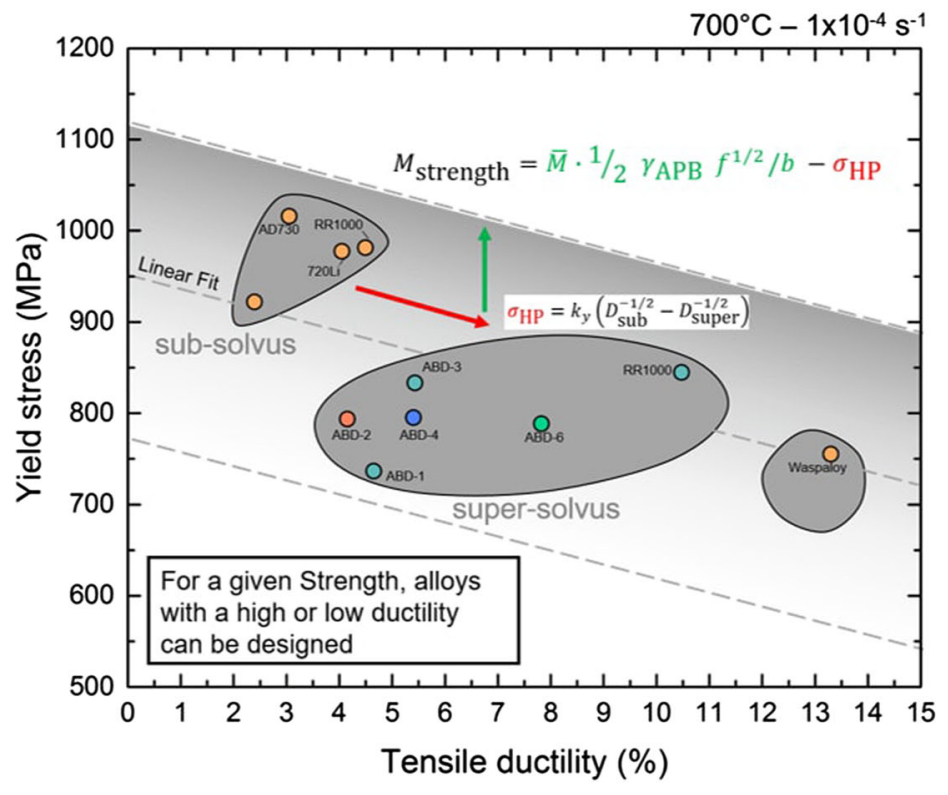

(a)

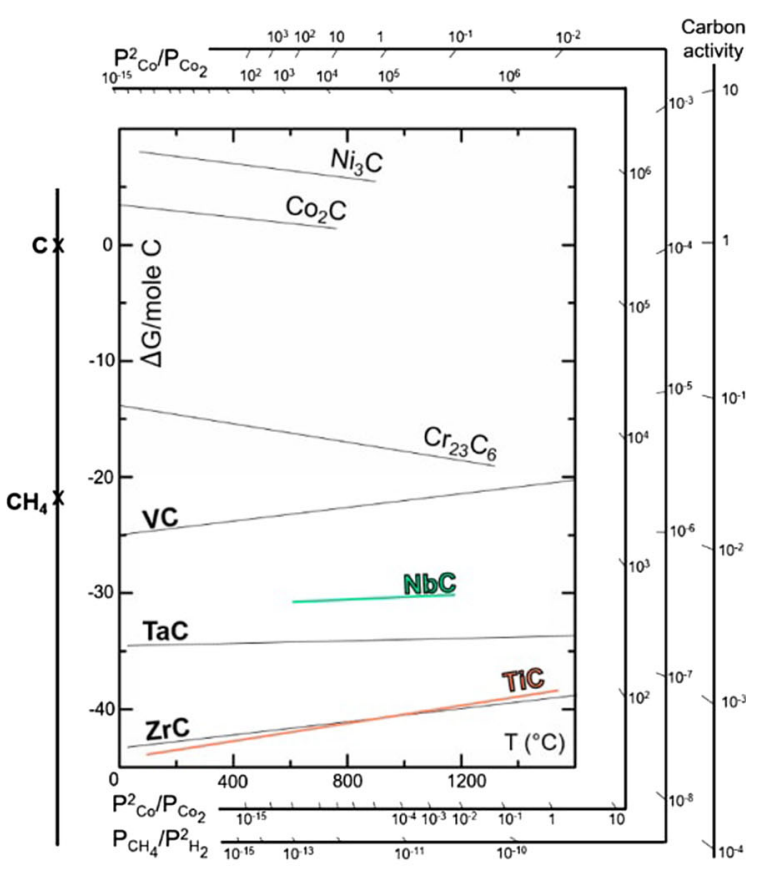

(b)

Fig. 12- (a) Yield stress and tensile ductility obtained from miniaturized ETMT tensile tests at $700{ }^{\circ} \mathrm{C}$ using a strain-rate of $1 \times 10^{-4} \mathrm{~s}^{-1}$ for various Ni-based superalloys illustrating that for a given strength alloys with a low and a high tensile ductility can be designed. It is shown that the loss in strength due to Hall-Petch has to be counteracted via an increase in precipitation strengthening and $\gamma^{\prime}$-phase volume fraction. (b) Ellingham diagram for carbides which commonly form in Ni-based superalloys. Reproduced with permission from Shatynski. ${ }^{[4]}$

The difference in carbide stability at $1170{ }^{\circ} \mathrm{C}$ is also seen in the carbide Ellingham diagram of Figure 12(b). Titanium is known to stabilize MC and hence retard its coarsening and dissolution. ${ }^{[4]}$ This is likely to suppress grain growth at lower $\mathrm{Nb} / \mathrm{Ti}$ ratio in for example alloy ABD-2. But accounting for the influence of alloy composition on grain size development during processing is a significant issue which should be the topic of future work.

\section{SUMMARY AND CONCLUSIONS}

In this work, three high-strength Ni-based superalloys of varying $\mathrm{Nb} / \mathrm{Ti}$ ratio have been studied. The following specific conclusions can be drawn:

(1) Differences in the $\mathrm{Nb} / \mathrm{Ti}$ ratio did not alter the yield stress of these alloys either at ambient conditions - at which it is $\sim 935 \mathrm{MPa}-$ or at $700{ }^{\circ} \mathrm{C}$ where it is reduced to $\sim 792 \mathrm{MPa}$. This occurs despite an influence of the increasing $\mathrm{Nb} /$ Ti ratio which coarsens the grain size from 18 to $45 \mu \mathrm{m}$; the mean diameter of both secondary and tertiary $\gamma^{\prime}$-precipitates is independent of $\mathrm{Nb} / \mathrm{Ti}$ ratio at 230 and $40 \mathrm{~nm}$, respectively.

(2) The above implies that any loss in Hall-Petch strengthening due to the increase in grain size as the $\mathrm{Nb} / \mathrm{Ti}$ ratio increases is offset by an increase in $\gamma$-matrix solid solution hardening and/or an increased resistance to $\gamma^{\prime}$-precipitate shearing.
Analysis via theoretical modeling has been used to rationalist the increments in strengthening due to these effects.

(3) In contrast, the tensile ductility at $700{ }^{\circ} \mathrm{C}$ is influenced substantially by the $\mathrm{Nb} / \mathrm{Ti}$ ratio due to an effect on the susceptibility to quasi-brittle intergranular cracking. Tensile ductility is no longer alloy independent and is approximately doubled from 4.2 pct for the smallest $\mathrm{Nb} / \mathrm{Ti}$ ratio examined (zero) to 7.8 pct for the largest (0.43). Consistent with this, the elevated temperature conditional fracture toughness calculated from interrupted single edge notched tests increases from 19.7 to $24.6 \mathrm{MPa} \sqrt{\mathrm{m}}$.

(4) Characterization of interrupted primary crack tips revealed sub-micron sized oxide intrusions which penetrate the grain boundaries. The size of the intrusions is found to be independent of the $\mathrm{Nb} / \mathrm{Ti}$ ratio. However, the oxide intrusions contain different phases present in an order consistent with thermodynamics. The internal oxidation of reactive elements found in $\gamma^{\prime}$-precipitates, $\mathrm{Al}_{2} \mathrm{O}_{3}$ and $\mathrm{TiO}_{2}$, are responsible for extending the environmental damage zone during steady-state crack propagation. Not observed are $\mathrm{Nb}$-rich oxides such as $\mathrm{NbO}_{2}$.

(5) Whilst all alloys investigated failed at $700{ }^{\circ} \mathrm{C}$ in a quasi-brittle fashion due to environmentally-assisted cracking, a coarse grain size increases both the tensile ductility and the fracture toughness. Crack bridging, crack deflection, and an increased 
resistance to grain boundary sliding play roles in this. In addition, evidence is presented which confirms that the tertiary $\gamma^{\prime}$-precipitate size and composition affect the susceptibility to environmentally-assisted cracking, since the dissolution of the tertiary $\gamma^{\prime}$-precipitates ahead of the crack is required to form $\mathrm{Al}_{2} \mathrm{O}_{3}$ and $\mathrm{TiO}_{2}$ at undamaged grain boundaries.

(6) The present study has implications for the design of damage-tolerant high-strength Ni-based superalloys. At any given strength level, our results demonstrate clearly that more or less damage-tolerant variants can be designed by subtle changes in alloy composition; for optimum resistance to environmentally-assisted cracking one should aim for a high yield stress and coarse grain size, in as much as the two can be varied independent of one another. The balance of the elements $\mathrm{Nb}$ and $\mathrm{Ti}$ needs to be chosen carefully in this regard.

\section{ACKNOWLEDGMENTS}

The financial support of this work via the Engineering and Physical Sciences Research Council (EP/ M50659X/1) and Rolls-Royce plc is acknowledged. In addition, André Németh would like to acknowledge Rolls-Royce plc. for the provision of material. David Armstrong acknowledges financial support from the Royal Academy of Engineering though a Research Fellowship. Roger Reed acknowledges funding from a Royal Society Industry Fellowship.

\section{OPEN ACCESS}

This article is distributed under the terms of the Creative Commons Attribution 4.0 International License (http://creativecommons.org/licenses/by/4.0/), which permits unrestricted use, distribution, and reproduction in any medium, provided you give appropriate credit to the original author(s) and the source, provide a link to the Creative Commons license, and indicate if changes were made.

\section{REFERENCES}

1. R. Jiang, D.J. Bull, D. Proprentner, B. Shollock, and P.A.S. Reed: Int. J. Fatigue, 2017, vol. 99, pp. 175-86, https://doi.org/10.1016/ j.ijfatigue.2017.03.003.

2. T.M. Pollock and S. Tin: J. Propuls. Power, 2006, vol. 22, pp. 361-74, https://doi.org/10.2514/1.18239.

3. S. Cruchley, H. Evans, and M. Taylor: Mater. High Temp., 2016, vol. 3409, pp. 1-11, https://doi.org/10.1080/09603409.2016. 1171952.

4. A.A.N. Németh, D.J. Crudden, D.E.J. Armstrong, D.M. Collins, K. Li, A.J. Wilkinson, C.R.M. Grovenor, and R.C. Reed: Acta Mater., 2017, vol. 126, pp. 361-71, https://doi.org/10.1016/ j.actamat.2016.12.039.

5. H.S. Kitaguchi, M.P. Moody, H.Y. Li, H.E. Evans, M.C. Hardy, and S. Lozano-Perez: Scripta Mater., 2015, vol. 97, pp. 41-44, https://doi.org/10.1016/j.scriptamat.2014.10.025.
6. L. Viskari, M. Hörnqvist, K.L. Moore, Y. Cao, and K. Stiller: Acta Mater., 2013, vol. 61, pp. 3630-39, https://doi.org/10.1016/ j.actamat.2013.02.050.

7. R.P. Wei, C.F. Miller, Z. Huang, G.W. Simmons, and D.G. Harlow: Eng. Fract. Mech., 2009, vol. 76, pp. 715-27, https:// doi.org/10.1016/j.engfracmech.2008.09.003.

8. M. Gao, D.J. Dwyer, and R.P. Wei: Scripta Metall. Mater., 1995, vol. 32, pp. 1169-74, https://doi.org/10.1016/0956-716X(95)00120$\mathrm{K}$.

9. H.Y. Li, J.F. Sun, M.C. Hardy, H.E. Evans, S.J. Williams, T.J.A. Doel, and P. Bowen: Acta Mater., 2015, vol. 90, pp. 355-69, https://doi.org/10.1016/j.actamat.2015.02.023.

10. J. Telesman, T.P. Gabb, and L.J. Ghosn: Superalloys, Wiley, Hoboken, 2016, pp. 549-60.

11. S. Antonov, J. Huo, Q. Feng, D. Isheim, D.N. Seidman, R.C. Helmink, E. Sun, and S. Tin: Scripta Mater., 2017, vol. 138, pp. 35-38, https://doi.org/10.1016/j.scriptamat.2017.05.028.

12. A.A.N. Németh, D.J. Crudden, D.M. Collins, D.E.J. Armstrong, and R.C. Reed: Superalloys, Wiley, Hoboken, 2016, pp. 80110 .

13. R.C. Reed, T. Tao, and N. Warnken: Acta Mater., 2009, vol. 57, pp. 5898-13, https://doi.org/10.1016/j.actamat.2009.08.018.

14. D.J. Crudden, A. Mottura, N. Warnken, B. Raeisinia, and R.C. Reed: Acta Mater., 2014, vol. 75, pp. 356-70, https://doi.org/ 10.1016/j.actamat.2014.04.075.

15. J.O. Andersson, T. Helander, L. Höglund, P. Shi, and B. Sundman: Calphad, 2002, vol. 26, pp. 273-312, https://doi.org/10.1016/S03645916(02)00037-8.

16. C.A. Schneider, W.S. Rasband, and K.W. Eliceiri: Nat. Methods, 2012, vol. 9, pp. 671-75, https://doi.org/10.1038/nmeth.2089.

17. D.M. Collins, D.J. Crudden, E. Alabort, T. Connolley, and R.C. Reed: Acta Mater., 2015, vol. 94, pp. 244-56, https://doi.org/ 10.1016/j.actamat.2015.04.046.

18. F. Wallow and E. Nembach: Scripta Mater., 1996, vol. 34, pp. 499-505, https://doi.org/10.1016/S0956-716X(95)00548-A.

19. L.A. Gypen and A. Deruyttere: J. Mater. Sci., 1977, vol. 12 (5), pp. 1028-33, https://doi.org/10.1007/BF00540987.

20. H.A. Roth, C.L. Davis, and R.C. Thomson: Metall. Mater. Trans. A, 1997, vol. 28A, pp. 1329-35, https://doi.org/10.1007/s11661997-0268-2.

21. Y. Mishima, S. Ochiai, N. Hamao, M. Yodogawa, and T. Suzuki: Trans. Jpn. Inst. Metals, 1986, vol. 27, pp. 656-64, https://doi.org/ 10.2320/matertrans1960.27.656.

22. E.I. Galindo-Nava, L.D. Connor, and C.M.F. Rae: Acta Mater., 2015, vol. 98, pp. 377-90, https://doi.org/10.1016/ j.actamat.2015.07.048.

23. B. Roebuck, D.C. Cox, and R.C. Reed: Superalloys, Wiley, Hoboken, 2004, pp. 523-28.

24. D.P. Rooke and D.J. Cartwright: Eng. Fract. Mech., 1976, vol. 8, pp. 567-73, https://doi.org/10.1016/0013-7944(76)90010-2.

25. P.D. Littlewood, T.B. Britton, and A.J. Wilkinson: Acta Mater., 2011, vol. 59, pp. 6489-6500, https://doi.org/10.1016/ j.actamat.2011.07.016.

26. M.C. Rezende, L.S. Araújo, S.B. Gabriel, J. Dille, and L.H. de Almeida: J. Alloys Compd., 2015, vol. 643, pp. 256-59, https:// doi.org/10.1016/j.jallcom.2014.12.279.

27. Gabb, T.P., Telesman, J., Banik, A., and McDevitt, E.: Proceedings of the Symposium on Superalloy 718 and Derivatives, 2014, pp. 697-712.

28. M. Calmunger, G. Chai, S. Johansson, and J. Moverare: Theor. Appl. Mech. Lett., 2014, vol. 4, pp. 0410041-46, https://doi.org/ $10.1063 / 2.1404104$.

29. H.S. Kitaguchi, H.Y. Li, H.E. Evans, R.G. Ding, I.P. Jones, G. Baxter, and P. Bowen: Acta Mater., 2013, vol. 61, pp. 1968-81, https://doi.org/10.1016/j.actamat.2012.12.017.

30. C.F. Miller, G.W. Simmons, and R.P. Wei: Scripta Mater., 2000, vol. 42, pp. 227-32, https://doi.org/10.1016/S1359-6462(99)00336$\mathrm{X}$.

31. C.F. Miller, G.W. Simmons, and R.P. Wei: Scripta Mater., 2003, vol. 48, pp. 103-08, https://doi.org/10.1016/S1359-6462(02)00355$\mathrm{X}$.

32. J. Telesman, P. Kantzos, J. Gayda, P.J. Bonacuse, and A. Prescenzi: Superalloys, Wiley, Hoboken, 2004, pp. 215-24.

33. S.T. Wlodek: Trans. Metall. Soc. AIME, 1964, vol. 230, pp. 1078-90. 
34. H.T. Pang and P.A.S. Reed: Mater. Sci. Eng. A, 2007, vol. 448, pp. 67-79, https://doi.org/10.1016/j.msea.2006.11.016.

35. S. Everitt, M.J. Starink, and P.A.S. Reed: Superalloys, Wiley, Hoboken, 2008, pp. 714-50.

36. R. Jiang, S. Everitt, M. Lewandowski, N. Gao, and P.A.S. Reed: Int. J. Fatigue, 2014, vol. 62, pp. 217-27, https://doi.org/10.1016/ j.ijfatigue.2013.07.014.

37. D. Gustafsson and E. Lundström: Int. J. Fatigue, 2013, vol. 48, pp. 178-86, https://doi.org/10.1016/j.ijfatigue.2012.10.018.

38. M. Hörnqvist, L. Viskari, K.L. Moore, and K. Stiller: Mater. Sci. Eng. A, 2014, vol. 609, pp. 131-40, https://doi.org/10.1016/ j.msea.2014.04.102.

39. U. Krupp, K. Wackermann, and H.-J. Christ: Magnus Hörnqvist Colliander, and Krystyna Stiller: OxidMet., 2017, vol. 88, pp. 3-14, https://doi.org/10.1007/s11085-016-9707-z.

40. R. Jiang and P.A.S. Reed: Mater. Sci. Technol., 2016, vol. 32, pp. 401-06, https://doi.org/10.1080/02670836.2016.1148227.
41. S.L. Mannan, K.G. Samuel, and P. Rodriguez: Mater. Sci. Eng., 1985, vol. 68, pp. 143-49, https://doi.org/10.1016/00255416(85)90403-3.

42. S. Floreen and R.H. Kane: Metall. Mater. Trans. A, 1976, vol. 7A, pp. 1157-60, https://doi.org/10.1007/BF02656598.

43. K. Maciejewski and H. Ghonem: Mater. Sci. Eng. A, 2013, vol. 560, pp. 439-49, https://doi.org/10.1016/j.msea.2012.09.088.

44. S.R Shatynski: Oxid. Metals, 1979, vol. 13, pp. 105-18, https:// doi.org/10.1007/BF00611975.

45. J. Telesman, T.P. Gabb, A. Garg, P. Bonacuse, and J. Gayda: Superalloys, Wiley, Hoboken, 2008, pp. 807-16.

46. G.H. Gessinger and M.J. Bomford: Int. Metall. Rev., 1974, vol. 19, pp. 51-76, https://doi.org/10.1179/imtlr.1974.19.1.51.

47. B. Piekarski: Mater. Charact., 2001, vol. 47, pp. 181-86, https:// doi.org/10.1016/S1044-5803(01)00166-8.

48. M.F. Ashby and K.E. Easterling: Acta Metall., 1982, vol. 30, pp. 1969-78, https://doi.org/10.1016/0001-6160(82)90100-6. 